Bryn Mawr College

Scholarship, Research, and Creative Work at Bryn Mawr

College

2018

\title{
Proton Spin-Lattice Relaxation in Organic Molecular Solids: Polymorphism and the Dependence on Sample Preparation
}

Peter A. Beckmann

Bryn Mawr College, pbeckman@brynmawr.edu

Jamie Ford

William Paul Malachowski

Bryn Mawr College, wmalacho@brynmawr.edu

Andrew R. McGhie

Curtis E. Moore

See next page for additional authors

Let us know how access to this document benefits you.

Follow this and additional works at: https://repository.brynmawr.edu/physics_pubs

Part of the Physics Commons

\section{Custom Citation}

Beckmann, Peter A., Jamie Ford, William P. Malachowski, Andrew R. McGhie, Curtis E. Moore, Arnold L.Rheingold, Gilbert J.Sloan, Steven T. Szewczyk. 2018. "Proton Spin-Lattice Relaxation in Organic Molecular Solids: Polymorphism and the Dependence on Sample Preparation." ChemPhysChem 19.18: 2423-2436.

This paper is posted at Scholarship, Research, and Creative Work at Bryn Mawr College. https://repository.brynmawr.edu/physics_pubs/140

For more information, please contact repository@brynmawr.edu. 
Authors

Peter A. Beckmann, Jamie Ford, William Paul Malachowski, Andrew R. McGhie, Curtis E. Moore, Arnold L. Rheingold, Gilbert J. Sloan, and Steven T. Szewczyk 


\section{${ }^{1} \mathrm{H}$ Spin-Lattice Relaxation in Organic Molecular Solids: Polymorphism and the Dependence on Sample Preparation}

Peter A. Beckmann, ${ }^{*}[a]$ Jamie Ford, ${ }^{[b]}$ William P. Malachowski, ${ }^{[c]}$ Andrew R. McGhie, ${ }^{[d]}$ Curtis E. Moore, ${ }^{\left[{ }^{[e]}\right.}$ Arnold L. Rheingold, ${ }^{[f]}$ Gilbert J. Sloan, ${ }^{[g]}$ and Steven T. Szewczyk ${ }^{[\mathrm{h}]}$

[a] Prof. P. A. Beckmann

Department of Physics, Bryn Mawr College

Bryn Mawr, Pennsylvania (USA)

email: pbeckman@brynmawr.edu

[b] Dr. J. Ford

Nanoscale Characterization Facility, Singh Center for Nanotechnology

University of Pennsylvania, Philadelphia, Pennsylvania (USA)

[c] Prof. W. P. Malachowski

Department of Chemistry, Bryn Mawr College

Bryn Mawr, Pennsylvania (USA)

[d] Dr. A. R. McGhie

Laboratory for Research on the Structure of Matter

University of Pennsylvania, Philadelphia, Pennsylvania (USA)

[e] Dr. C. E. Moore

Department of Chemistry and Biochemistry

University of California San Diego, La Jolla, California (USA)

[f] Prof. A. L. Rheingold

Department of Chemistry and Biochemistry

University of California San Diego, La Jolla, California (USA)

[g] Dr. G. J. Sloan

Laboratory for Research on the Structure of Matter

University of Pennsylvania, Philadelphia, Pennsylvania (USA)

[h] Dr. S. T. Szewczyk

Department of Materials Science and Engineering

School of Engineering and Applied Science

University of Pennsylvania, Philadelphia, Pennsylvania (USA)

ChemPhysChem, 2018, vol 19, pages 2423-2436 


\section{Abstract}

We report solid state nuclear magnetic resonance ${ }^{1} \mathrm{H}$ spin-lattice relaxation, single-crystal X-ray diffraction, powder X-ray diffraction, field emission scanning electron microscopy, and differential scanning calorimetry in solid samples of 2-ethylanthracene (EA) and 2ethylanthraquinone (EAQ) that have been physically purified in different ways from the same commercial starting compounds. The solid state ${ }^{1} \mathrm{H}$ spin-lattice relaxation is always nonexponential at high temperatures as expected when $\mathrm{CH}_{3}$ rotation is responsible for the relaxation. The ${ }^{1} \mathrm{H}$ spin-lattice relaxation experiments are very sensitive to the "several-molecule" (clusters) structure of these van der Waals molecular solids. In the three differently prepared samples of $E A Q$, the relaxation also becomes very nonexponential at low temperatures. This is very unusual and the decay of the nuclear magnetization can be fitted with both a stretched exponential and a double exponential. This unusual result correlates with the powder X-ray diffractometry results and suggests that the anomalous relaxation is due to crystallites of two (or more) different polymorphs (concomitant polymorphism).

\section{Introduction}

Solid state ${ }^{1} \mathrm{H}$ nuclear magnetic resonance (NMR) spin-lattice relaxation experiments [14] exploit the long-range nature of the ${ }^{1} \mathrm{H}-{ }^{1} \mathrm{H}$ dipolar (spin-spin) interaction to gain insight into the relationship between dynamics and structure on the mesoscopic (severalmolecule or cluster) level in van der Waals solids composed of covalently bonded molecules. This mesoscopic realm, which includes polymorphism [5-7] (especially concomitant polymorphism [8]) or crystallinity versus glassy states $[9,10]$ is still an important frontier.

When methyl group rotation is responsible for the ${ }^{1} \mathrm{H}$ spin-lattice relaxation, the relaxation can be nonexponential and this allows for more stringent tests of the relaxation models and for the identification of inhomogeneities in the structure of the pure solid [1114]. In this report we investigate two closely related molecular solids where different procedures for preparing very pure samples, along with ${ }^{1} \mathrm{H}$ spin-lattice relaxation experiments, result in different, but reproducible, results from sample to sample. To aid in the interpretation of the unusual relaxation results in the various samples, we have 
performed single crystal X-ray diffraction [15], powder X-ray diffractometry [16, 17], differential scanning calorimetry [18], high resolution NMR spectroscopy [19, 20], gas chromatography-mass spectrometry, and field emission scanning electron microscopy [21]. The compounds under investigation are 2-ethylanthracene (EA) and 2ethylanthraquinone (EAQ) (Figure 1). We have investigated two samples of EA and four samples of $E A Q$, all prepared differently from the same supplied commercial stock. They are solids well above room temperature, the samples produced in different ways are very stable over long times, they are all very pure, and there are no solid-solid phase transitions in the temperature regions studied by the solid state NMR relaxation experiments. These samples are indicated in Table 1. The experiments reported here are consistent with our previously reported, less precise, experiments in these two compounds [22].

\section{Data Analysis}

\subsection{Single-crystal X-ray Diffraction}

The single crystal X-ray diffraction data for 2-ethylanthraquinone (EAQ) and 2ethylanthracene (EA) are presented in Table 2. For EAQ, a single crystal was taken from sample EAQ0 and for EA a single crystal was taken from sample EA1 (see Table 1). Samples EA2, EAQ1, EAQ2, and EAQ3 simply did not have crystals large enough for single-crystal $X$-ray analysis. The structures of the EAQ and EA molecules in these crystals are shown in Figure 1 and the crystal structures of the two compounds are shown in Figure 2. The structures have been deposited with the Cambridge Structural Database and the deposit numbers are 1537735 (EAQ) and 1538277 (EA). As indicated in Figures 1 and 2 , the asymmetric unit is a single molecule $(Z=1)$ for this polymorph of EAQ and two molecules $(Z=2)$ for what is, as far as we can tell, the only structure for $E A$. The methyl groups in both compounds are well out of the aromatic plane; $78^{\circ}$ in EAQ and $73^{\circ}$ (molecule A) and $57^{\circ}$ (molecule B) in EA. [For comparison, gas phase microwave spectroscopy [23, 24], supersonic molecular jet spectroscopy [25, 26], liquid state NMR spin-spin coupling constants analyses [27], gas phase electron diffraction studies [28], and molecular orbital calculations [29] all consistently show that, in the gas and liquid phases, the preferred orientation (i.e., the lowest-energy configuration) of the ethyl group 
in ethylbenzene-like systems corresponds to the methyl group oriented $90^{\circ}$ to the plane.] Given these orientations of the methyl groups, there will be both intramolecular (predominantly intraethyl) and intermolecular contributions to the barrier for methyl group rotation [30-32].

\subsection{Powder X-ray Diffraction}

Powder X-ray diffractograms were observed and compared with diffractograms computed from the single-crystal $X$-ray experiments. The broad backgrounds were very similar for all the powder X-ray diffractograms [17] and were removed. The experimental and computed diffractograms have different line broadenings and thus peak heights cannot be directly compared. Figure 3 shows a comparison between the powder X-ray diffractogram for $10 \mathrm{mg}$ of sample EA1 (red line) and the diffractogram computed from the single crystal $X$-ray structure (black line) determined using a small single crystal taken from sample EA1. This comparison indicates that sample EA1 is entirely composed of crystallites whose structure was determined using the very small single crystal. This comparison also indicates that the sample is very pure.

Figure 4 shows powder X-ray diffractograms for samples EAQ1 (red line), EAQ2 (purple line) and EAQ3 (blue line), along with the computed diffractogram (black line) from the single crystal $X$-ray structure determination using a small crystal taken from sample EAQ0. The comparison indicates that a $10 \mathrm{mg}$ sample taken from sample EAQ1 is almost entirely composed of crystallites whose structure was determined using a very small single-crystal from sample EAQ0. There are small but significant differences between the computed diffractogram using a crystal taken from sample EAQ0 (black line) and the experimental diffractograms using about $10 \mathrm{mg}$ of samples EAQ2 (purple line) and EAQ3 (blue line). All samples are very pure and these comparisons indicate the presence of crystallites composed of at least one additional polymorph in samples EAQ2 and EAQ3 in addition to the one found in samples EAQ0 and EAQ1. The powder diffractograms offer no information, however, on how much of each polymorph might be present in each sample since much of the spectrum is likely to be similar or the same from one polymorph to the other. 


\subsection{High-resolution NMR Spectroscopy and Gas Chromatography-Mass Spectrometry.}

High-resolution NMR spectroscopy experiments at $400 \mathrm{MHz}$ and gas chromatography mass spectrometry (GC-MS) experiments were conducted in all five samples used in the solid state NMR relaxation experiments (see Table 1) and indicate no perceptible impurities at the level of resolution for these techniques.

\subsection{Differential Scanning Calorimetry}

The approximately $10 \mathrm{mg}$ of sample used for the differential scanning calorimetry (DSC) experiments were taken from the actual samples (all approximately $0.7 \mathrm{~g}$ ) already used in the NMR relaxation experiments. This means that, starting at room temperature (292-297 $\mathrm{K})$, the two samples of EA had been taken up and down in temperature between $93 \mathrm{~K}$ and $320 \mathrm{~K}$, and the three samples of EAQ had been taken up and down in temperature between 105 and $286 \mathrm{~K}$, all many times over a period of five years, prior to the DSC scans. No solid-solid phase transitions were observed in four of the five samples. One high-temperature phase transition was observed in sample EA2 as presented below.

Sample EA1 melted at $427 \mathrm{~K}$ with a latent heat of melting of $90 \mathrm{~J} / \mathrm{g}$. It showed no evidence (see below) of polymorphism. For sample EA2, there was a small endotherm $(14 \mathrm{~J} / \mathrm{g})$ at $362 \mathrm{~K}$ and on melting there was a double peak. The first peak $(413 \mathrm{~K})$ was very small $(1.2 \mathrm{~J} / \mathrm{g})$ with the main melting peak coming at $425 \mathrm{~K}$ with a latent heat of melting of $93 \mathrm{~J} / \mathrm{g}$. The phase transition at $362 \mathrm{~K}$ is well above $320 \mathrm{~K}$, the highest temperature that this sample had ever been taken to in the NMR relaxation experiments.

Sample EAQ1 melted at $381 \mathrm{~K}$ with a latent heat of melting of $64 \mathrm{~J} / \mathrm{g}$. The sharp melting curve is consistent with the sample being predominantly composed of a single polymorph. The NMR relaxation results presented in Section 2.6.5 suggest that a second polymorph is present at the level of $10 \pm 5 \%$.

Sample EAQ2 gave two melting peaks, one at $380 \mathrm{~K}$ with a latent heat of melting of $58 \mathrm{~J} / \mathrm{g}$, and the second at $383 \mathrm{~K}$ with a latent heat of melting of $39 \mathrm{~J} / \mathrm{g}$, suggesting the presence of two polymorphs. These melting temperatures are far above room temperature (293-297 K), the highest temperature this recrystallized sample had been to prior to this DSC experiment. The ratio of the polymorphs, assuming similar heats of 
melting (since they melt at approximately the same temperature) are approximately $60 \%$ to $40 \%$. These results are consist with the NMR relaxation results that find two polymorphs in approximately a $50 \%-50 \%$ ratio in the sample before it was first melted. On quenching from the melt to room temperature and reheating through the melt, only one sharp phase transition was found at $382 \mathrm{~K}$ with a latent heat of melting of $87 \mathrm{~J} / \mathrm{g}$. This suggests that the quench from the melt resulted in a single polymorph.

Sample EAQ3 melted at $379 \mathrm{~K}$ with a latent heat of melting of $81 \mathrm{~J} / \mathrm{g}$ but the melt was broader than the other samples. On quenching from the melt to room temperature and reheating through the melt, a very sharp phase transition was found at $379 \mathrm{~K}$ with a latent heat of melting of $75 \mathrm{~J} / \mathrm{g}$. These results, taken together, are consistent with the sample, before the first melt, having more than one polymorph with very close melting points. This is consist with the NMR relaxation results that find two polymorphs in approximately a $50 \%-50 \%$ ratio in the sample before it was first melted.

All the melting (or remelting) transitions were very sharp. In agreement with the other techniques, these results indicate that all the samples are very pure. We note that if some samples contain more than one polymorph, once a sample is melted, it is a "different" sample. The absence of solid-solid phase transitions at temperatures up to the highest temperatures used in the solid state NMR relaxation experiments imply that the structure determined by single-crystal $\mathrm{X}$-ray diffraction at room temperature for sample $E A 1$ and at $100 \mathrm{~K}$ for sample EAQ0 is valid for the entire temperature range of the solid state ${ }^{1} \mathrm{H}$ spin-lattice relaxation experiments described in Section 2.6. In some cases solidsolid phase transitions show up clearly in NMR spin-lattice relaxation experiments as discontinuities in the relaxation rate versus temperature [32-36] but sometimes there is no indication [37-39]. But differential scanning calorimetry is definitive [37, 38].

\subsection{Scanning Electron Microscopy}

Field emission scanning electron microscopy (SEM) was performed on all five samples used in the solid state NMR relaxation experiments. Figure 5 shows images of (a small part of) sample EA1, Figure 6 shows images of (a small part of) sample EAQ1, and Figure 7 shows images of (a small part of) sample EAQ3. SEM images for samples EA2, and EAQ2 are similar and are not shown. All these images are very unusual and very 
difficult to interpret unambiguously. Normally, at the spatial resolution indicated in part (b) of these figures, at least some structures that are clearly single crystals can be seen in these types of organic solids [12, 40,41] but that is not the case here. All these images suggest structures that may or may not be single crystals and that, if they are single crystals, the crystals have a smallest dimension (thickness) that is $100 \mathrm{~s} \mathrm{~nm}$ or less.

\subsection{Solid State ${ }^{1} \mathrm{H}$ Spin-lattice Relaxation}

\subsubsection{Introduction: General Features}

In both $E A$ and $E A Q$, the dominant solid state ${ }^{1} \mathrm{H}$ spin-lattice relaxation mechanism involves methyl group rotation modulating the six ${ }^{1} \mathrm{H}-{ }^{1} \mathrm{H}$ spin-spin interactions among the three ${ }^{1} \mathrm{H}$ spins in a methyl group [42]. In the solid state, the ethyl groups, like isopropyl groups [43], are static on the NMR time scale, meaning that the NMR activation energy for rotation is over approximately $60 \mathrm{~kJ} \mathrm{~mol}^{-1}$ which is to be compared to the methyl group activation energies in the $8-18 \mathrm{~kJ} \mathrm{~mol}^{-1}$ for molecules like those studied here [12, 30, 40, 44]. The quenching of ethyl and isopropyl group rotation in the solid state results from intermolecular interactions $[45,46]$ and the rotational asymmetry of ethyl and isopropyl groups. [Ethyl and isopropyl group rotational barriers in isolated molecules (the gas phase) similar to that studied here $[24,27,47]$ are in the $1-8 \mathrm{~kJ} \mathrm{~mol}^{-1}$ range.] In contrast, $t$-butyl groups, though more bulky, do orient on the NMR time scale in the solid state with activation energies in the 8-36 kJ mol-1 range [48-50] as a consequence of their three-fold rotational symmetry.

When methyl group rotation is responsible for ${ }^{1} \mathrm{H}$ spin-lattice relaxation (or ${ }^{19} \mathrm{~F}$ spin-lattice relaxation for a trifluoromethyl group [51]) in the solid state, nonexponential relaxation is expected at temperatures above the maximum in the relaxation rate and at temperatures in the vicinity of the relaxation rate maximum $[52,53]$. This phenomenon is a result of cross correlations among the three spin-1/2 protons (or three spin-1/2 ${ }^{19} \mathrm{~F}$ nuclei) and is well understood [52, 53] and well established experimentally [51 54-58]. The relaxation becomes more exponential if the methyl group rotation axis is reorienting, such as in a $t$-butyl group [48, 49] or for whole-molecule rotation [57, 59-61]. It also becomes more exponential if $\mathrm{CH}_{3}-$ non- $\mathrm{CH}_{3}{ }^{1} \mathrm{H}-{ }^{1} \mathrm{H}$ interactions play a significant role [57 $59,62]$. Finally, at temperatures well below the maximum in the relaxation rate, the 
relaxation becomes exponential within experimental uncertainty. The experiments in the two samples of EA are as expected in that they follow this pattern. The nonexponential relaxation reported here at low temperatures in all three samples of EAQ is both unexpected and unusual and is one major focus of this paper, as discussed in Sections 2.6.4 and 2.6.5.

\subsubsection{Modeling the Initial Relaxation Rates $R$}

When methyl group rotation is responsible for nonexponential relaxation at high temperatures and at temperatures in the vicinity of the relaxation rate maximum, it is the initial (i.e., short time following a perturbation of the ${ }^{1} \mathrm{H}$ magnetization) relaxation rate $R s$ [63] that is to be modeled [52]. The temperature $T$ dependences of the initial relaxation rates $R$ s for sample EA1 of 2-ethylanthracene and sample EAQ1 of 2-ethylanthraquinone are shown as red circles on a $\ln R s$ versus $T^{-1}$ plot in Figure 8 . The relaxation in both EA1 and EAQ1 was nonexponential at higher temperatures as expected.

The basic model [64-69], when applied to the initial relaxation rate $R \mathrm{~s}$ as required [52], is [42] $R \mathrm{~S}=C\left[J_{\mathrm{DCC}}(\omega, \tau \mathrm{DC})+4 J_{\mathrm{DC}}(2 \omega, \tau \mathrm{DC})\right]$ with $\operatorname{JDC}(\omega, \tau \mathrm{DC})=(2 / \omega)[\sin \{\varepsilon \arctan (\omega \tau \mathrm{DC})\}] /\left[\left(1+\omega^{2} \tau \tau^{2}\right)^{\varepsilon / 2}\right], \tau \mathrm{DC}=\tau_{\infty}\left[\exp \left\{E_{\mathrm{DC}} / k T\right\}\right]$, $\tau_{\infty}=x(2 \pi / 3)\left(2 / / E_{\mathrm{DC}}\right)^{1 / 2}$, and $C=y(n / M)(9 / 40)[\mu \mathrm{O} /(4 \pi)]^{2}\left(\hbar \gamma^{2} / r^{3}\right)^{2}$. We note that we do not need to consider the quantum mechanical tunneling of methyl groups at the high temperatures encountered here $[39,65,70-78] . \operatorname{JCC}(\omega, \tau)$ is the Davidson-Cole spectral density $[42,79]$ (thus all the DC subscripts), $\omega /(2 \pi)=22.5 \mathrm{MHz}$ is the NMR frequency, $\tau \mathrm{DC}$ is the DavidsonCole cutoff mean time between methyl group hops in a semiclassical (thermally activated) methyl group hopping process for methyl groups in the perfect crystal environment, $\varepsilon$ is a parameter that characterizes a Davidson-Cole distribution of NMR activation energies $E$ with $E_{\mathrm{DC}}$ being an upper limit cutoff [42, 49], I is the moment of inertia of a methyl group, $n=3$ is the number of ${ }^{1} \mathrm{H}$ spins in a methyl group, $N(=14$ for EA and 12 for EAQ) is the number of ${ }^{1} \mathrm{H}$ spins in the molecule [80-82], $\mu \mathrm{o}$ is the magnetic constant, $\gamma$ is the ${ }^{1} \mathrm{H}$ magnetogyric ratio, and $r$ is the $\mathrm{H}-\mathrm{H}$ distance in a methyl group. The parameter $C$ with $y=$ 1 can be calculated with no adjustable parameters [42] and accounts for the strength of the ${ }^{1} \mathrm{H}$ spin-lattice relaxation resulting from the modulation of the ${ }^{1}{ }^{1}{ }^{1} \mathrm{H}-{ }^{1} \mathrm{H}$ spin-spin 
interactions in a methyl group (the intramethyl contribution). The phenomenological fitting parameter $y \geq 1$ accounts for the contribution of the modulation of the spin-spin interactions between ${ }^{1} \mathrm{H}$ spins in a methyl group and other ${ }^{1} \mathrm{H}$ spins (both intramolecular and intermolecular) (see Eq. 6 in ref 83). It is important that the $\mathrm{H}-\mathrm{H}$ distance in a methyl group $r$ as determined by electronic structure calculations [40] is used since single-crystal X-ray diffraction finds distances that are approximately $10 \%$ too short $[84,85]$.

The parameter $\tau_{\infty}$ with $x=1$ results from a somewhat simplistic model for the preexponential factor that assumes that between hops the methyl group is vibrating as a harmonic oscillator at the bottom of the rotational potential [86]. The parameter $x$ is simply a phenomenological fitting parameter that accounts for departure from this simple model. This model, with the parameter $x$, is a useful benchmark and guide. Finally, we note that the NMR activation energy $E$ is closely related to, but not exactly the same as, the barrier $V$ for rotation of a methyl group. The relationship between $V$ and $E$ is complicated and numerical models suggest that $E$ is between 0 and $20 \%$ smaller than $V$ for activation energies $E$ in the range being investigated here [87, 88].

For 2-ethylanthracene (sample EA1), $E_{\mathrm{DC}}=16.0 \pm 1.6 \mathrm{~kJ} \mathrm{~mol}^{-1}, \varepsilon=0.53 \pm 0.11$, $y=1.6 \pm 0.3$, and $x=0.30 \pm 0.15$. For 2-ethylanthraquinone (sample $E A Q 1), E_{\mathrm{DC}}=17.5 \pm 1.8 \mathrm{~kJ}$ $\mathrm{mol}^{-1}, \varepsilon=0.60 \pm 0.12, y=1.3 \pm 0.3$ and $x=0.50 \pm 0.25$. With one caveat, standard iterative (Simplex) fitting procedures were used that involve estimating initial parameters and then minimizing the difference in the sum of squares between the predicted and experimental $\ln R s$ versus $T^{-1}$ values. The caveat is that the values of the four parameters produced in these procedures have unrealistically small uncertainties. As such, one of the four values was fixed at a value that was a certain percentage difference from the "best" value and the algorithm was rerun allowing the other three parameters to find new best values. This was done for different percentages involving all four parameters and the subsequent fits were inspected visually. Though somewhat unorthodox, we feel this an intellectually honest way to proceed. The final uncertainties produced are significantly larger than those produced by the initial minimization routine. The large uncertainties in $x$ result from the fact that $E_{\mathrm{DC}}$ was ultimately assigned a $10 \%$ uncertainty and is in an exponential $\tau \mathrm{DC}=\tau_{\infty}\left[\exp \left\{E_{\mathrm{DC}} / k T\right\}\right]$ with $\tau_{\infty}=x(2 \pi / 3)\left(2 / / E_{\mathrm{DC}}\right)^{1 / 2}$. This means that $\tau_{\infty}$ has about a $40 \%$ uncertainty and $x$ has about a 50\% uncertainty. NMR relaxation experiments, even with 
high signal-to-noise do a poor job of determining the preexponential factor $\tau_{\infty}$ accurately when realistic fitting procedures are employed.

\subsubsection{A Distribution of Activation Energies}

The model presented in Section 2.6.2 that predicts $\varepsilon<1$ is the Davidson-Cole spectral density $\operatorname{JDC}(\omega, \tau \mathrm{DC})=(2 / \omega)[\sin \{\varepsilon \arctan (\omega \tau \mathrm{DC})\}] /\left[\left(1+\omega^{2} \tau \mathrm{DC}^{2}\right)^{\varepsilon / 2}\right]$ and it interprets $\varepsilon$ as a parameter that characterizes a distribution of $\tau$ values with $\tau \mathrm{DC}$ being an upper-limit cutoff value corresponding to the perfect crystal environment. Via $\tau=\tau_{\infty}[\exp \{E / k T\}]$, a distribution of NMR activation energies $E$ with an upper-limit value of $E_{\mathrm{DC}}$, can be determined [42]. In the limit $\varepsilon \rightarrow 1, \operatorname{JDC}(\omega, \tau \mathrm{DC})=(2 / \omega)[\sin \{\varepsilon \arctan (\omega \tau \mathrm{DC})\}] /\left[\left(1+\omega^{2} \tau \mathrm{DC}^{2}\right)^{\varepsilon / 2}\right] \rightarrow$

2 TPoisson $/\left(1+\omega^{2} \tau_{\text {Poisson }}^{2}\right)$ with $\tau$ Poisson $=\tau \mathrm{DC}$ (for $\varepsilon=1$ ) being a single, unique mean time between hops characterizing a single Poisson distribution of times between hops.

Distributions of NMR activation energies for $\varepsilon=0.63$ and 0.79 for 80 and $250 \mathrm{~K}$ are plotted in reference 13 and for $\varepsilon=0.85$ and $100 \mathrm{~K}$ in reference 43 . This model suggests that for $\varepsilon=0.63$, for example, $20 \%$ of the methyl groups have an NMR activation energy $E$ that is less that $90 \%$ of the ideal crystal value $E_{\mathrm{DC}}$. The model suggests that the methyl groups with lower barriers (than those in the ideal crystal structure) reside on the surfaces of crystallites or near other crystal imperfections. This is consistent with the SEM images (section 2.5) that show the crystallites have (at least) one dimension that is very small. In reference [13] we provide a back-of-the-envelop calculation that indicates that if crystallites have one dimension of $100 \mathrm{~nm}$ then $10 \%$ of the molecules would have an NMR activation energy different from EDC. One could invent other symmetric distributions of NMR activation energies (other than the Davidson Cole distribution) involving Gaussians $[90,91]$ or Lorentzians but then the spectral density would have to be computed numerically. This is being considered for future work. There are many other phenomenological spectral densities that can be expressed algebraically [92], most from dielectric relaxation studies, but none fit data like that presented in Figure 8. 


\subsubsection{Stretched Exponential Relaxation: The Characteristic Relaxation Rates $\boldsymbol{R}^{\star}$ and the Stretching Parameters $\beta$}

If the relaxation of the ${ }^{1} \mathrm{H}$ magnetization $M(t)$ following a perturbation is exponential, it can be characterized by $M(t)=M(\infty)+[M(0) \square M(\infty)][\exp \{-(R t)\}]$ with adjustable parameters $M(\infty)$ (the equilibrium magnetization), $M(0)$ (the initial magnetization following a perturbation), and $R$ (the unique relaxation rate). Ideally, $M(0)=-M(\infty)$ for a perturbation $\pi$-pulse (Section 5.6) but the pulse is not perfect and if $M(0)$ is not taken as an independent adjustable parameter, significant systematic errors in the other adjustable parameters can result. This single-exponential function works well for both samples of EA at low temperatures. In all cases when the relaxation is nonexponential, the entire relaxation curves in both samples of EA and all three samples of EAQ at all temperatures could always be fitted to a stretched exponential $M(t)=M(\infty)+[M(0)-M(\infty)]\left[\exp \left\{-\left(R^{\star} t\right)^{\beta}\right\}\right]$. This is a purely phenomenological representation [93-95] and is used to interpret experimental results in many fields of physical science [91, 96-123]. There are four adjustable parameters for each recovery curve; $M(\infty), M(0), R^{\star}$, and $\beta . R^{\star}$ is the "characteristic relaxation rate" and $\beta$ is the "stretching parameter". The parameters $R^{\star}$ and $\beta$ are not amenable to interpretation by any closed-form NMR relaxation model as far as we are aware but measuring $R^{\star}$ and $\beta$ can be done quickly and $R^{\star}$ can be determined accurately, usually to $\pm 3 \%$. As such, $R^{\star}$ is a good phenomenological parameter to use to compare various samples and $\beta$ is a good parameter to quantify the degree of nonexponentiality.

$R^{\star}$ and $\beta$ were measured for all samples. $\operatorname{Ln} R^{\star}$ versus $T^{-1}$ is shown as red squares in Figure 8 for samples EA1 and EAQ1 where $\ln R$ s (red circles) versus $T^{-1}$ (discussed in Section 2.6.2) is also shown for comparison. $R^{\star} \leq R$ s always. Ln $R^{\star}$ versus $T^{-1}$ and $\beta$ versus $T^{-1}$ are shown as squares in Figure 9 for samples EA1 and EA2 and in Figure 10 for samples EAQ1, EAQ2, and EAQ3. Based on many previous experiments [40, 58], $\beta$ versus $T^{-1}$ can be expected to lie within the two purple lines in Figures $9 \mathrm{~b}$ and $10 \mathrm{~b}$. For $\mathrm{EA}, \beta$ versus $T^{-1}$ for both samples EA1 and EA2 in Figure $9 \mathrm{~b}$ is as expected [58] (or nearly so) but the different $\beta$ versus $T^{-1}$ data for all three samples of EAQ at low temperatures in Figure 10b is unusual. 


\subsubsection{Double Exponential Relaxation in all EAQ Samples at Low Temperatures}

In addition to being fitted by a stretched exponential (which cannot be fitted to an algebraic model), the solid state relaxation rate data in samples EAQ1, EAQ2, and EAQ3 (at lower temperatures only) can also be fitted to a double exponential;

$M(t)=M_{1}(t)+M_{2}(t)=M_{1}(\infty)+\left[M_{1}(0)-M_{1}(\infty)\right]\left[\exp \left\{-\left(R_{1} t\right)\right\}\right]+M_{2}(\infty)+\left[M_{2}(0)-M_{2}(\infty)\right]\left[\exp \left\{-\left(R_{2} t\right)\right\}\right]$ which is a five-parameter fit; relaxation rates $R_{1}$ and $R_{2}$, equilibrium magnetizations $M_{1}(\infty)$ and $M_{2}(\infty)$, and initial magnetization $M(0)=M_{1}(0)+M_{2}(0)$ where not both $M_{1}(0)$ and $M_{2}(0)$ are independent. It is convenient to replace the two absolute equilibrium magnetizations $M_{1}(\infty)$ and $M_{2}(\infty)$ with the fractional equilibrium magnetizations $\phi_{1}=M_{1}(\infty) /\left[M_{1}(\infty)+M_{2}(\infty)\right]$ and $\phi_{2}=M_{2}(\infty) /\left[M_{1}(\infty)+M_{2}(\infty)\right]$. The two rates $R_{1}$ and $R_{2}$ are shown as triangles in Figure $11 \mathrm{a}$ at temperatures below $142 \mathrm{~K}$ for the three samples of EAQ where the stretched exponential rates in Figure 10a are also shown as small squares for comparison. The fractional equilibrium magnetizations $\phi_{1}$ and $\phi_{2}$ are shown in Figure 11b. A double exponential will not fit the relaxation rate data for the three EAQ samples at temperatures above $142 \mathrm{~K}$ or the two EA samples at any temperature. These double exponential fits for the three samples of EAQ are modeled in Section 3.3: the two magnetizations correspond to two different polymorphs.

The reason that the $R^{\star}$ values in samples EAQ2 and EAQ3 (blue and purple squares in Figures 10a and 11a) are greater than the $R^{\star}$ values in sample EAQ1 (red squares) is now clear. The $R_{2}$ values for the second polymorph (downward pointing triangles in Figure 11a) are greater than the $R_{1}$ values for the first polymorph (upward pointing triangles). The presence of the second polymorph at approximately the $50 \%$ level in samples EAQ2 and EAQ3 makes the characteristic rate $R^{\star}$ values greater in these samples. Indeed, they are roughly half way between the $R_{1}$ and the $R_{2}$ values. Since there is only approximately $10 \%$ of the second polymorph in sample EA1, the $R^{\star}$ values are smaller and very similar to the $R_{1}$ values in that sample.

\section{Results and Discussion}

\subsection{General Comments}

The great strength of the solid state ${ }^{1} \mathrm{H}$ NMR spin-lattice relaxation technique as employed in this study is that it investigates properties related to the dynamics of methyl 
group rotation and as such can be used to learn about anisotropies in the methyl groups' intramolecular and intermolecular environments. The technique uses large samples $(0.7 \mathrm{~g}$ in our case) and because of the long range nature of the ${ }^{1} \mathrm{H}-{ }^{-1} \mathrm{H}$ spin-spin interaction, and the interesting complexities associated with the nonexponential relaxation, these experiments can probe inhomogeneities in macroscopic samples. There are two distinct types of inhomogeneities as presented in Sections 3.2 and 3.3. The models developed to interpret the NMR relaxation results are aided greatly by the several other experimental techniques employed in this study.

\subsection{The Consequences of Very Small Crystallites}

In all five samples studied by NMR relaxation, there is a distribution of activation energies for methyl group rotation with only a small fraction of methyl groups having an activation energy different from the majority of methyl groups which have a unique single NMR activation energy. This strongly suggests a type of inhomogeneity on the microscopic scale and is consistent with those molecules near a crystallite surface or other crystal imperfection having methyl groups with a rotational barrier different from the majority of methyl groups on molecules in the ideal crystal structure. This interpretation is supported by the field emission scanning electron microscopy experiments. This distribution of activation energies $E$ involves methyl groups on molecules that are evenly spread out throughout the sample (on crystal surfaces and at other crystal imperfections) and are nearby molecules that have the bulk crystal activation energy $E_{\mathrm{DC}}$. This is because this model requires rapid spin-diffusion among all ${ }^{1} \mathrm{H}$ nuclei.

\subsection{The Presence of Two Polymorphs in Solid 2-Ethylanthraquinone}

The above discussion pertains to both samples of 2-ethylanthracene (EA) and all three samples of 2-ethylenthraquinone (EAQ) investigated by solid state NMR relaxation in this study. In the three samples of EAQ, however, there is a different and additional type of structural inhomogeneity. In this case, at low temperatures, the NMR relaxation following a suitable perturbation is well fitted by a double exponential (Section 2.6.5) suggesting that the sample is made up of two different sets of regions consisting of molecules with different environments. These two regions do not communicate with each other via the 
long-range ${ }^{1} \mathrm{H}-{ }^{1} \mathrm{H}$ spin-spin (dipolar) interaction, making it very different from the type of inhomogeneity discussed in Section 3.2. A region arbitrarily labeled Region One in all three samples, characterized by the relaxation rate $R_{1}$, is the one that corresponds to the quantitative fits produced for sample EAQ1: compare the red upward pointing triangles $\left(R_{1}\right)$ with the red squares $\left(R^{\star}\right)$ in Figure $11 \mathrm{a}$. As Figure $11 \mathrm{~b}$ indicates, $90 \pm 5 \%$ of this sample is composed of Region One. In sample EAQ2, $50 \pm 15 \%$ of the sample is Region One and in sample EAQ3, $50 \pm 10 \%$ of the sample is Region One. We suggest that Region One involves the normal region characterized by the determined crystal structure for sample EAQ0 (Section 2.1 and Figures 1 and 2). For molecules in the other region, arbitrarily labeled Region Two, the relaxation rates are larger (faster relaxation). It is not possible to disentangle the parameters that characterize methyl group relaxation for Region Two because of the limited temperature region spanned by the data.

We exclude the interpretation (of the relaxation rate data) for the two regions in the three samples of EAQ that suggests there may be some parts of the sample that are in a non-crystalline (glassy) state. This is unlikely because the powder X-ray experiments (Section 2.2) use about $10 \mathrm{mg}$ of each of the three samples of EAQ and show crystalline structures for all three samples. Glasses produce very different powder X-ray diffractograms with much less structure. A second and more likely interpretation is that the two regions are both crystalline in nature but correspond to different polymorphs; so called concomitant polymorphism [8]. High-resolution ${ }^{1} \mathrm{H}$ NMR spectroscopy, gas chromatography-mass spectrometry, powder X-ray diffractometry, and differential scanning calorimetry indicate that the samples are all very pure with impurity levels significantly below the level that would affect the solid state ${ }^{1} \mathrm{H}$ NMR spin-lattice relaxation measurements. We rule out impurities. Although the powder X-ray diffractograms clearly show that the dominant polymorph in sample EAQ1 (Region One) is present in samples EAQ2 and EAQ3, it may or may not be the case that Region Two in the three samples is the same polymorph. It may even be that Region Two contains more than one polymorph. Solid state ${ }^{13} \mathrm{C}$ NMR spectroscopy may be helpful in identifying different polymorphs in samples such as those studied here [124].

The anomalous NMR relaxation results in the three samples of EAQ are only observed at low temperatures. There are five pieces of evidence that suggest the 
presence of more than one polymorph suggested by these low-temperature NMR relaxation results is the case for all temperatures and that this concomitant polymorphism is very stable. First, NMR relaxation is much more sensitive (and usually only sensitive) to this kind of structural inhomogeneity in this low-temperature long-correlation time limit where the mean time between "events" (methyl group $2 \pi / 3$ hops) is long compared with the inverse NMR frequency. Second, the differential scanning calorimetry data presented in Section 2.4 shows no solid-solid phase transitions in any of the EAQ samples at temperatures all the way to the melting points (which are much higher temperatures than any of the NMR relaxation experiments were performed). Third, the powder X-ray crystallography diffractograms presented in Section 2.2 use about $10 \mathrm{mg}$ of sample and are very slightly different for the three samples of EAQ. Fourth, the NMR relaxation experiments in the various samples are completely reproducible within the uncertainties in the fitted parameters over long periods. Relaxation experiments were conducted over a period of five years going up and down in temperature many times and going back and forth among the various samples. The fifth piece of evidence is the fact that the first time (10 mg of) samples EAQ2 and EAQ3 were melted in the differential scanning calorimetry experiments (after the solid state NMR relaxation experiments were completed), either a double melting peak (sample EAQ2) or a broadened melting peak (sample EAQ3) was observed but on solidification and then remelting, very sharp single peaks were observed in both samples.

\section{Conclusions}

NMR relaxation experiments and several supporting experimental techniques have been used to investigate the relationship between methyl group rotation and structure in macroscopic polycrystalline samples of 2-ethylanthracene (EA) and 2-ethylanthraquinone (EAQ). Methyl groups in the ideal crystal environments rotate with activation energies (similar to rotational barriers) of $18 \mathrm{~kJ} \mathrm{~mol}^{-1}$ in the single polymorph of EA and $16 \mathrm{~kJ} \mathrm{~mol}^{-1}$ in one polymorph of EAQ. The crystallites in the polycrystalline samples are very small and methyl groups near crystallite surfaces or near other crystal imperfections have barriers that are slightly smaller. EA exists in one polymorph but macroscopic samples of EAQ have two (or more) polymorphs that are present in different amounts depending on 
the manner of sample preparation. The samples prepared using different procedures are stable over periods of (at least) several years and are very pure.

\section{Experimental Procedures}

\subsection{Sample Preparations and Designations}

The compound 2-ethylanthracene (EA) was purchased from Sigma-Aldrich (quoted purity $98 \%$, mp $152-153^{\circ} \mathrm{C}$ ). The compound 2-ethylanthraquinone (EAQ) was purchased from Sigma-Aldrich (quoted purity $97 \%, \mathrm{mp} 108-111^{\circ} \mathrm{C}$ ). Two samples of EA and four samples of $E A Q$ were prepared.

Sample EA1 was zone refined and then sublimed. Zone refining (also called zone melting) $[125,126]$ is a purification technique in which material to be purified is cast in a right circular cylinder. A small heater, typically $0.05-0.1$ times the length of the cylindrical sample, is moved from top to bottom of the cylinder, at a temperature just high enough to melt the material being treated. As the heater melts a new segment of the sample, it leaves behind a solid which is purer than the starting material because impurities are retained in the molten zone. The critical benefit of this procedure is that it can be carried out iteratively, with each zone passage carrying additional impurity, so that high purity can be attained. Further, the operation can be carried out in sealed containers, thereby avoiding effects of air, moisture, etc.

Samples EA2 and EAQ0 were sublimed. Sample EAQ1 was recrystallized by cooling a solution of 2-propanol from $75^{\circ} \mathrm{C}$ to $25^{\circ} \mathrm{C}$ at $2^{\circ} \mathrm{C}$ per hour. Sample EAQ2 was recrystallized in the same manner after being zone refined and sample EAQ3 was grown from the melt using the Bridgman method [127]. These samples are presented in Table 1.

\subsection{Single-crystal X-ray Diffraction}

A single crystal of 2-ethylanthracene was taken from sample EA1 and a single crystal of 2-ethylanthraquinone was taken from sample EAQ0. They were mounted on Hampton CryoLoops with Paratone-N oil and data collected with a Bruker D8 diffractometer using an Ultra rotating-anode generator (Mo) equipped with a high-efficiency, multi-layer, double-bounce monochromator. All data were collected with $1.0 \mathrm{sec} / 1.0^{\circ}$ correlated scans. Structure solution and subsequent refinement used various components of the 
SHELXTL software package distributed by the Bruker Corporation (G. Sheldrick, BrukerAXS, Madison WI). Structure and refinement parameters are presented in Table 2 and the molecular and crystal structures are presented in Figures 1 and 2 and discussed in Section 2.1.

\subsection{Powder X-ray Diffraction}

Powder X-ray diffractograms were observed using sample EA1 of 2-ethylanthrancene and samples EAQ1, EAQ2, and EAQ3 of 2-ethylanthraquinone. The samples (approximately $10 \mathrm{mg}$ ) were ground to a thick paste in mineral oil and spread evenly on a fine Nylon loop. Data were recorded using a Cu rotating-anode source and a Vantac 500 detector at 100K. The data is presented in Figures 3 and 4 and discussed in Section 2.2.

\subsection{Differential Scanning Calorimetry}

Samples EA1, EA2, EAQ1, EAQ2, and EAQ3, all about $0.7 \mathrm{~g}$, were used in the solid state NMR relaxation experiments. Differential scanning calorimetry (DSC) was performed using about $10 \mathrm{mg}$ from each of these samples on a TA Instruments Q2000 to characterize thermal transitions. The temperature was taken quickly from room temperature (approximately $297 \mathrm{~K}$ ) down to approximately $120 \mathrm{~K}$ and from there to just above the melting points (all above $380 \mathrm{~K}$ ) at $5 \mathrm{~K}$ /minute under a helium purge. Temperature and enthalpy calibrations were made using indium, and baseline corrections were determined from sapphire standards. The data is discussed in Section 2.4.

\subsection{Field Emission Scanning Electron Microscopy}

Field emission scanning electron microscopy was performed with all samples except sample EAQ0 (see Table 1) using a FEI Quanta 600FEG Field Emission Scanning Electron Microscope. Particles were randomly sprinkled on carbon tape. As such we were able to achieve a variety of orientations for the particles. This potentially allowed for a determination of the smallest particle dimension because some particles were imbedded on the carbon tape in an edge-on orientation. The electron beam energy was $5 \mathrm{keV}$ and the images were taken under 0.38 Torr air pressure. Images are shown in Figures 5, 6, and 7 and discussed in Section 2.5. 


\subsection{Solid State ${ }^{1} \mathrm{H}$ Spin-lattice Relaxation}

${ }^{1} \mathrm{H}$ spin-lattice relaxation measurements were performed using a (perturbation $\pi$ )- $t$ (observe $\pi / 2$ )- $t_{w}$ pulse sequence at an NMR frequency of $22.5 \mathrm{MHz}$ with both samples of EA (EA1 and EA2) between 93 and $290 \mathrm{~K}$ and three samples of EAQ (EAQ1, EAQ2, and EAQ3) between 105 and $320 \mathrm{~K}$. The wait time $t_{w}$ was always ten times (or more) longer than the largest relaxation time being measured. Temperature control and measurement is discussed extensively elsewhere [63]. The characteristic relaxation rates $R^{\star}$ and the stretching parameters $\beta$ characterizing the stretched exponential were determined for all samples throughout the temperature ranges indicated above and are presented in Figures 8-11 and discussed in Section 2.6.4. The initial relaxation rates $R s$ were determined for samples EA1 and samples EAQ1 at all temperatures indicated above and are presented in Figure 8 and discussed in Section 2.6.2. Relaxation rates $R_{1}$ and $R_{2}$ in a double exponential relaxation process were determined in the three samples of $E A Q$ below $142 \mathrm{~K}$. These data are presented in Figure 11 and discussed in Section 2.6.5.

\section{References}

[1] R. Kimmich, NMR Tomography, Diffusometry, Relaxometry, Springer-Verlag, Berlin, 1997.

[2] R. R. Ernst, G. Bodenhausen, A. Wokaum, Principles of Nuclear Magnetic Resonance in One and Two Dimensions, Oxford Univ. Press, Oxford, 1987.

[3] C. P. Slichter, Principles of Magnetic Resonance, 3rd ed., Springer-Verlag, Berlin, 1990.

[4] A. Abragam, The Principles of Nuclear Magnetism, Oxford Univ. Press, Oxford, 1961.

[5] J. Bernstein, Polymorphism in Molecular Crystals, Oxford Univ. Press, Oxford, UK, 2002.

[6] C. E. Hughes, P. A. Williams, T. R. Peskett, K. D. H. Harris, J Phys. Chem. Lett. 2012, 3, 3176-3181.

[7] P. A. Beckmann, K. S. Burbank, K. M. Clemo, E. N. Slonaker, K. Averill, C. Dybowski, J. S. Figueroa, A. Glatfelter, S. Koch, L. M. Liable-Sands, A. L. Rheingold, J. Chem.

Phys. 2000, 113, 1958-1965.

[8] J. Bernstein, R. J. Davey, J.-O. Benck, Angew. Chem. Int. Ed. 1999, 38, 3440-3461.

[9] M. T. Myaing, L. Sekaric, P. A. Beckmann, Z. Naturforsch. 1997, 52a, 757-764.

[10] J. A. Weiss, P. A. Beckmann, Sol. State Nuc. Mag. Resonan. 2000, 16, 239-244. 
[11] D. Kruk, A. Korpala, E. Rossler, K. A. Earle, W. Medycki, J. Moscicki, J. Chem. Phys. 2012, 136, 114504, 1-8.

[12] P. A. Beckmann, C. W. Mallory, F. B. Mallory, A L. Rheingold, X. Wang, ChemPhysChem 2015, 16, 1509-1519.

[13] P. A. Beckmann, K. G. Conn, C. W. Mallory, F. B. Mallory, A. L. Rheingold, L. Rotkina, X. Wang, J. Chem. Phys. 2013, 139, 204501, 1-12.

[14] R. Meier, D. Kruk, J. Gmeiner, E. A. Rossler, J. Chem. Phys. 2012, 136, 034508,1-8.

[15] R. Tilley, Crystals and Crystal Structures, Wiley, Chichester, UK, 2006.

[16] A. Clearfield, J. H. Reibenspies, N. Bhuvanesh, eds., Principles and Applications of Powder Diffraction, Wiley-Blackwell, Chichester, U. K., 2008.

[17] R. E. Dinnebier, S. J. L. Billinge, eds., Powder Diffraction Theory and Practice, RSC Publishing, Cambridge, U. K., 2008.

[18] G. W. H. Höhne, W. F. Hemmingger, H. -J. Flammersheim, Differential Scanning Calorimetry, 2nd ed., Springer-Verlag, Berlin, 2003.

[19] R. M. Silverstein, F. X. Webster, D. J. Kiemle, D. L. Bryce, Spectroscopic Identification of Organic Compounds, 8th ed., Wiley, New York, 2014.

[20] N. E. Jacobsen, NMR Spectroscopy Explained: Simplified Theory, Applications, and Examples for Organic Chemistry and Structural Biology, Wiley, Hoboken, NJ, 2007.

[21] J. Goldstein, D. E. Newbury, D. C. Joy, C. E. Lyman, P. Echlin, E. Lifshin, L. Sawyer, J. R. Michael, Scanning Electron Microscopy and X-ray Microanalysis, 3rd ed., Springer Science + Business Media, New York, 2003.

[22] P. A. Beckmann, K. S. Burbank, M. M. W. Lau, J. N. Ree, T. L. Weber, Chem. Phys. 2003, 290, 241-250.

[23] B. Maté, R. D. Suenram, C. Lugez, J. Chem. Phys. 2000, 113, 192-199.

[24] N. S. True, M. S. Farag, R. K. Bohn, M. A. MacGregor, J. J. Radhakrishnan, J. Phys. Chem. 1983, 87, 4622-4627.

[25] J. I. Seeman, H. V. Secor, P. J. Breen, V. H. Grassian, E. R. Bernstein, J. Am. Chem. Soc. 1989, 111, 3140-3150.

[26] P. J. Breen, E. R. Bernstein, J. I. Seeman, J. Chem. Phys. 1987, 87, 3269-3275.

[27] T. Schaefer, L. Kruczynski, W. Niemczura, Chem. Phys. Lett. 1976, 38, 498-499.

[28] P. Scharfenberg, B. Rozsondai, I. Hargittai, Z. Naturforsch. 1980, 35a, 431-436.

[29] W. J. Hehre, L. Radom, J. A. Pople, J. Am. Chem. Soc. 1972, 94, 1496-1504.

[30] X. Wang, P. A. Beckmann, C. W. Mallory, A. L. Rheingold, A. G. DiPasquale, P. J. Carroll, F. B. Mallory, J. Org. Chem. 2011, 76, 5170-5176.

[31] W. I. Hembree, J. Baudry, J. Phys. Chem. B, 2011, 115, 8575-8580.

[32] E. O. Stejskal, D. E. Woessner, T. C. Farrar, H. S. Gutowsky, J. Chem. Phys. 1959, 31, 55-65. 
[33] A. Birczyński, E. E. Ylinen, M. Punkkinen, A. M. Szymocha, Z. T. Lalowic, Sol. State Nuc. Mag. Resonan. 2008, 34, 77-85.

[34] M. Grottel, M. Szafrański, Z. Pajak, Z. Naturforsch. 1997, 52a, 783-788.

[35] P. A. Beckmann, A. J. Leffler, J. Chem. Phys. 1980, 72, 4600-4607.

[36] S. Albert, J. A. Ripmeester, J. Chem. Phys. 1973, 58, 541-548.

[37] P. A. Beckmann, A. R. McGhie, A. L. Rheingold, G. J. Sloan, S. T. Szewczyk, J. Phys. Chem. A 2017, 121, 6220-6230.

[38] J. Przesławski, W. Medycki, A. Piecha, R. Jakubas, D. Kruk, Chem. Phys. 2013, 410, 19-24.

[39] K. J. Mallikarjunaiah, K. J. Singh, K. P. Ramesh, R. Damle, Magn. Resonan. Chem. 2008, 46, 110-114.

[40] P. A. Beckmann, J. M. Bohen, J. Ford, W. P. Malachowski, C. W. Mallory, F. B. Mallory, A. R. McGhie, A. L. Rheingold, G. J. Sloan, S. T. Szewczyk, X. Wang, K. A. Wheeler, Sol. State Nuc. Mag. Resonan. 2017, 85, 1-11.

[41] X. Wang, L. Rotkina, H. Su, P. A. Beckmann, ChemPhysChem 2012, 13, 2082-2089. [42] P. A. Beckmann, L. Happersett, A. V. Herzog, W. M. Tong, J. Chem. Phys. 1991, 95, 828-835.

[43] X. Wang, A. L. Rheingold, A. G. DiPasquale, F. B. Mallory, C. W. Mallory, P. A. Beckmann, J. Chem. Phys. 2008, 128, 124502, 1-3.

[44] C. A. Buser, C. W. Mallory, F. B. Mallory, J. Mosher, Sol. State Nuc. Mag. Resonan. 1998, 12, 251-256.

[45] A. Stone, Theory of Intermolecular Forces, Oxford Univ. Press, Oxford, 2013.

[46] A. Otera-de-la-Roza, E. R. Johnson, J. Chem. Phys. 2012, 137, 054103, 1-10.

[47] D. M. Gasparro, D. R. P. Almeida, S. M. Dobo, L. L. Torday, A. Varro, J. G. Papp, J. Molec. Struct. 2002, 585, 167-179.

[48] P. A. Beckmann, C. E. Moore, A. L. Rheingold, Phys. Chem. Chem. Phys. 2016, 18, 1720-1726.

[49] X. Wang, F. B. Mallory, C. W. Mallory, H. R. Odhner, P. A. Beckmann, J. Chem. Phys. 2014, 140, 194304, 1-15.

[50] A. M. Nishchenko, D. I Kolokolov, A. G. Stepanov, J. Phys. Chem. A 2011, 115, 7428-7436.

[51] P. A. Beckmann, A. L. Rheingold, J. Chem. Phys. 2016, 144, 154308, 1-12.

[52] R. L. Hilt, P. S. Hubbard, Phys. Rev. 1964, 134, A392-A398.

[53] L. K. Runnels, Phys. Rev. 1964, 134, A28-A36.

[54] J. D. Cutnell, W. Venable, J. Chem. Phys. 1974, 60, 3795-3801.

[55] J. D. Cutnell, L. Verduin, J. Chem. Phys. 1973, 59, 258-262.

[56] M. Mehring, H. Raber, J. Chem. Phys. 1973, 59, 1116-1120. 
[57] M. F. Baud, P. S. Hubbard, Phys. Rev. 1968, 170, 384-390.

[58] P. A. Beckmann, Sol. State Nuc. Mag. Resonan. 2015, 71, 91-95.

[59] L. J. Burnett, B. H. Muller, Chem. Phys. Lett. 1973, 18, 553-556.

[60] P. S. Hubbard, J. Chem. Phys. 1969, 51, 1647-1651.

[61] S. Albert, J. A. Ripmeester, J. Chem. Phys. 1972, 57, 2641-2645.

[62] A. Kumar, C. S. Johnson, Jr., J. Chem. Phys. 1974, 60, 137-146.

[63] P. A. Beckmann, E. Schneider, J. Chem. Phys. 2012, 136, 054508, 1-9.

[64] A. G. Redfield, IBM J. Res. Develop. 1957, 1, 19; reprinted with minor revisions in Advan. Mag. Resonan. 1965, 1, 1-32.

[65] E. O. Stejskal, H. S. Gutowsky, J. Chem. Phys. 1958, 28, 388-396.

[66] F. Bloch, Phys. Rev. 1957, 105, 1206-1222.

[67] F. Bloch, Phys. Rev. 1956, 102, 104-135.

[68] D. E. Woessner, J. Chem. Phys. 1962, 36, 1-4.

[69] R. K. Wangsness, F. Bloch, Phys. Rev. 1953, 89, 728-739.

[70] M. N. Ramanuja, K. P. Ramesh, J. Ramakrishna, Molec. Phys. 2009, 107, 643-652.

[71] S. Clough, Sol. State Nuc. Mag. Resonan. 1997, 9, 49-53.

[72] M. J. Barlow, S. Clough, A. J. Horsewill, M. A. Mohammed, Sol. State Nuc. Mag. Resonan. 1992, 1, 197-204.

[73] S. Clough, Physica B 1986, 136, 145-149.

[74] D. Cavagnat, S. Clough, F. O. Zelaya, J. Phys. C 1985, 18, 6457-6462.

[75] S. Clough, P. J. McDonald, F. O. Zelaya, J. Phys. C 1984, 17, 4413-4420.

[76] S. Clough, P. J. McDonald, J. Phys. C 1982, 15, L1039-L1042.

[77] S. Clough, A. Heidemann, A. J. Horsewill, J. D. Lewis, M. N. J. Paley, J. Phys. C 1981, 14, L525-L529.

[78] S. Clough, A. Heidemann, J. Phys. C 1980, 13, 3585-3589.

[79] D. W. Davidson, R. H. Cole, J. Chem. Phys. 1951, 19, 1484-1490.

[80] N. Bloembergen, L. O. Morgan, J. Chem. Phys. 1961, 34, 842-850.

[81] D. W. McCall, D. C. Douglass, Polymer, 1963, 4, 433-444.

[82] J. E. Anderson, W. P. Slichter, J. Phys. Chem. 1965, 69, 3099-3104.

[83] P. A. Beckmann, J. Rosenberg, K. Nordstrom, C. W. Mallory, F. B. Mallory, J. Phys. Chem. A 2006, 110, 3947-3953.

[84] V. L. Deringer, V. Hoepfner, R. Dronskowski, Cryst. Growth \& Design 2012, 12, 1014-1021.

[85] T. Steiner, W. Saenger, Acta Cryst. A 1993, 49, 379-384. 
[86] N. L. Owen, in Internal Rotation in Molecules, ed. W. J. Orville-Thomas, Wiley, New York, 1974.

[87] J. Kowalewski, T. Liljefors, Chem. Phys. Lett. 1979, 64, 170-174.

[88] O. Edholm, C. Blomberg, Chem. Phys. 1981, 56, 9-14.

[89] C. Kittel, Introduction to Solid State Physics, 8th ed., Wiley, USA, 2005.

[90] G. Stoch, E. E. Ylinen, A. Birczyński, Z. T. Lalowicz, K.Gora-Marek, M. Punkkinen, Sol. State Nuc. Mag. Resonan. 2013, 49-50, 33-41.

[91] S. Adhikari, M. Selmke, F. Cichos, Phys. Chem. Chem. Phys. 2011, 13, 1849-1856.

[92] P. A. Beckmann, Phys. Rep. 1988, 171, 85-128.

[93] R. Kohlrausch, Ann. Phys. Chem. (Poggendorff) 1854, 91, 179-214.

[94] M. Berberan-Santos, E. N. Bodunov, B. Valeur, Ann. Phys. (Berlin) 2008, 17, 460461.

[95] G. Williams, D. C. Watts, Trans. Far. Soc. 1970, 66, 80-85.

[96] N. Bodunov, Yu. A. Antonov, A. L. Simões Gamboa, J. Chem. Phys. 2017, 146, 114102, 1-8.

[97] C. Merschjann, M. Imlau, H. Brüning, B. Schoke, S.Torbrügge, Phys. Rev B 2011, 84, 052302, 1-4.

[98] S. Adhikari, M. Selmke, F. Cichos, Phys. Chem. Chem. Phys. 2011, 13, 1849-1856.

[99] T. Shiroka, F. Casola, V. Glazkov, A. Zheludev, K.Prsa, H. -R. Ott, J. Mesot, Phys. Rev. Lett. 2011, 106, 137202, 1-4.

[100] M. Potuzak, R. C. Welch, J. C. Mauro, J. Chem. Phys. 2011, 135, 214502, 1-7.

[101] E. G. Brandt, O. Edholm, J. Chem. Phys. 2010, 133, 115101, 1-12.

[102] R. Kahlau, D. Kruk, Th. Blochowicz, V. N. Novikov, E. A. Rossler, J. Phys.:

Condensed Matter, 2010, 22, 365101, 1-6.

[103] M. Krutyeva, J. Martin, A. Arbe, J. Colmenero, C. Mijangos, G. J. Schneider, T. Unruh, Y. Su, D. Richter, J. Chem. Phys. 2009, 131, 174901, 1-11.

[104] D. A. Turton, K. Wynne, J. Chem. Phys. 2009, 131, 201101, 1-4.

[105] T. C. Dotson, J. Budzien, J. D. McCoy, D. B. Adolf, J. Chem. Phys. 2009, 130, 024903, 1-9.

[106] J. G. Powles, D. M. Heyes, G. Rickayzen, W. A. B. Evans, J. Chem. Phys. 2009, 131, 214509, 1-8.

[107] M. N. Berberan-Santos, Chem. Phys. Lett. 2008, 460, 146-150.

[108] L. Wang, R. Liu, W. H. Wang, J. Chem. Phys. 2008, 128, 164503, 1-5.

[109] M. N. Berberan-Santos, E. N. Bodunov, B. Valeur, Chem. Phys. 2005, 315, 171182.

[110] V. Halpern, J. Chem. Phys. 2006, 124, 214508, 1-6. 
[111] K. L. Ngai, Phys. Rev. B, 2005, 71, 214201, 1-9.

[112] J. R. Macdonald, J. C. Phillips, J. Chem. Phys. 2005, 122, 074510, 1-8.

[113] M. Vogel, C. Brinkmann, H. Eckert, A. Heuer, Phys. Rev. B 2004, 69, 094302, 1-5. [114] J. C. Phillips, Rep. Prog. Phys. 1996, 59, 1133-1207.

[115] M. D. Ediger, C. A. Angell, S. R. Nagel, J. Phys. Chem. 1996, 100, 13200-13212.

[116] C. M. Roland, K. L. Ngai, J. Chem. Phys. 1995, 103, $1152-1159$.

[117] M. T. Cicerone, M. D. Ediger, J. Phys. Chem. 1995, 103, 5684-5692.

[118] D. L. Sidebottom, P. F, Green, R. K. Brow, J. Non-Cryst. Sol. 1995, 183, 151-160.

[119] K. L. Ngai, J. Non-Cryst. Sol. 1993, 162, 268-274.

[120] J. L. Skinner, J. Chem. Phys. 1983, 79, 1955-1964.

[121] E. Helfand, J. Chem. Phys. 1983, 78, 1931-1934.

[122] C. P. Lindsey, G. D. Patterson, J. Chem. Phys. 1980, 73, 3348-3357.

[123] C. T. Moynihan, L. P. Boesch, N.L. Laberge, Phys. Chem. Glasses 1973, 13, 122125.

[124] B. E. Padden, M. T. Zell, Z. Dong, S. A. Schroeder, D. J. W. Grant, E. J. Munson, Anal. Chem. 1999, 71, 3325-3331.

[125] G. J. Sloan, A. McGhie, Techniques of Melt Crystallization, Series Techniques of Chemistry, Vol. XIX, Wiley-Interscience, New York, 1988.

[126] W. G. Pfann, Zone Melting $2^{\text {nd }}$ ed., John Wiley, 1966.

[127] C. H. L. Goodman, Crystal Growth Theory and Techniques Vol. 1; Plenum: London, 1974. 


\section{Table 1. Information for the Samples Used}

\begin{tabular}{|c|c|c|c|}
\hline Compound & Sample & Preparation & Uses and Figures \\
\hline \multirow[t]{2}{*}{$\begin{array}{l}\text { 2-ethyl- } \\
\text { anthracene } \\
\text { (EA) }\end{array}$} & EA1 & $\begin{array}{l}\text { zone refined, } \\
\text { then sublimed }\end{array}$ & $\begin{array}{l}\text { Fig. 1d,e,f. single crystal X-ray; asymmetric unit } \\
\text { Fig. 2c,d. single crystal X-ray; crystal structure } \\
\text { Fig. 3. powder X-ray (red line) } \\
\text { Fig. 5. scanning electron microscopy images } \\
\text { Fig. 8a. } R \text { s (red circles), } R^{\star} \text { (red squares) } \\
\text { Fig. 9a. } R^{\star} \text { (red squares) } \\
\text { Fig. 9b. } \beta \text { (red squares) }\end{array}$ \\
\hline & EA2 & sublimed & $\begin{array}{l}\text { Fig. 9a. } R^{\star} \text { (blue squares) } \\
\text { Fig. 9b. } \beta \text { (blue squares) }\end{array}$ \\
\hline \multirow{4}{*}{$\begin{array}{l}\text { 2-ethyl- } \\
\text { anthraquinone } \\
\text { (EAQ) }\end{array}$} & EAQ0 & sublimed & $\begin{array}{l}\text { Fig. 1a,b,c. single crystal X-ray; asymmetric unit } \\
\text { Fig. 2a,b. } \\
\text { single crystal X-ray; crystal structure }\end{array}$ \\
\hline & EAQ1 & recrystallized & $\begin{array}{ll}\text { Fig. 4. } & \text { powder X-ray (red line) } \\
\text { Fig. 6. } & \text { scanning electron microscopy images } \\
\text { Fig. 8b. } & R s \text { (red circles), } R^{\star} \text { (red squares) } \\
\text { Fig. 10a. } & R^{\star} \text { (red squares) } \\
\text { Fig. 10b. } \beta \text { (red squares) } \\
\text { Fig. 11a. } R^{\star} \text { (red squares) } \\
\\
\quad R_{1} \text { (red upward-pointing triangles) } \\
\\
R_{2} \text { (red downward-pointing triangles) } \\
\text { Fig. 11b. } \phi_{1} \text { (red upward-pointing triangles) } \\
\\
\phi_{2} \text { (red downward-pointing triangles) }\end{array}$ \\
\hline & EAQ2 & $\begin{array}{l}\text { zone refined } \\
\text { then } \\
\text { recrystallized }\end{array}$ & $\begin{array}{ll}\text { Fig. 4. } & \text { powder X-ray (purple line) } \\
\text { Fig. 10a. } R^{\star} \text { (purple squares) } \\
\text { Fig. 10b. } \beta \text { (purple squares) } \\
\text { Fig. 11a. } R^{\star} \text { (purple squares) } \\
\\
R_{1} \text { (purple upward-pointing triangles) } \\
& R_{2} \text { (purple downward-pointing triangles) } \\
\text { Fig. 11b. } \phi_{1} \text { (purple upward-pointing triangles) } \\
\\
\quad \phi_{2} \text { (purple downward-pointing triangles) }\end{array}$ \\
\hline & EAQ3 & $\begin{array}{l}\text { from the melt } \\
\text { (bridgman } \\
\text { method) }\end{array}$ & $\begin{array}{ll}\text { Fig. 4. } & \text { powder X-ray (blue line) } \\
\text { Fig. 7. } & \text { scanning electron microscopy images } \\
\text { Fig. 10a. } & R^{\star} \text { (blue squares) } \\
\text { Fig. 10b. } \beta \text { (blue squares) } \\
\text { Fig. 11a. } R^{\star} \text { (blue squares) } \\
\\
\quad R_{1} \text { (blue upward-pointing triangles) } \\
\quad R_{2} \text { (blue downward-pointing triangles) } \\
\text { Fig. 11b. } \phi_{1} \text { (blue upward-pointing triangles) } \\
\quad \phi_{2} \text { (blue downward-pointing triangles) }\end{array}$ \\
\hline
\end{tabular}


Table 2. Crystal data and structure refinements

2-ethylanthraquinone 2-ethylanthracene

\begin{tabular}{|c|c|c|}
\hline CCDC identification code & 1537735 & 1538277 \\
\hline crystal taken from sample & EAQ0 & EA1 \\
\hline empirical formula & $\mathrm{C}_{16} \mathrm{H}_{12} \mathrm{O}_{2}$ & $\mathrm{C}_{16} \mathrm{H}_{14}$ \\
\hline formula weight & 236.26 & 206.27 \\
\hline temperature & $100(2) \mathrm{K}$ & 298(2) K \\
\hline wavelength & $0.71073 \AA$ & $0.71073 \AA$ \\
\hline crystal system & orthorhombic & monoclinic \\
\hline space group & P 212121 & P 21 \\
\hline \multirow[t]{6}{*}{ unit cell dimensions } & $a=4.397(4) \AA$ & $a=11.8795(13) \AA$ \\
\hline & $b=7.709(7) \AA$ & $b=7.8020(7) \AA$ \\
\hline & $c=34.49(3) \AA$ & $c=12.9533(15) \AA$ \\
\hline & $\alpha \square=90^{\circ}$ & $\alpha \square=90^{\circ}$ \\
\hline & $\beta \square=90^{\circ}$ & $\beta \square=106.785(8)^{\circ}$. \\
\hline & $\gamma=90^{\circ}$ & $\gamma=90^{\circ}$ \\
\hline volume & $1169.3(18) \AA^{3}$ & $1149.4(2) \AA^{3}$ \\
\hline$Z$ & 4 & 4 \\
\hline$Z^{\prime}$ & 1 & 2 \\
\hline density (calculated) & $1.342 \mathrm{Mg} / \mathrm{m}^{3}$ & $1.192 \mathrm{Mg} / \mathrm{m}^{3}$ \\
\hline absorption coefficient & $0.088 \mathrm{~mm}^{-1}$ & $0.067 \mathrm{~mm}^{-1}$ \\
\hline$F(000)$ & 496 & 440 \\
\hline crystal size & $0.280 \times 0.100 \times 0.070 \mathrm{~mm}^{3}$ & $0.417 \times 0.353 \times 0.278 \mathrm{~mm}^{3}$ \\
\hline$\theta$ range for data collection & 2.707 to $25.375^{\circ}$ & 1.642 to $23.257^{\circ}$ \\
\hline Index ranges & $-3 \leq h \leq 4,-9 \leq k \leq 8,-41 \leq k 39$ & $\begin{array}{l}-13 \leq h \leq 13,-8 \leq k \leq 8, \\
-14 \leq 1 \leq 14\end{array}$ \\
\hline reflections collected & 4311 & 3294 \\
\hline independent reflections & $1884[R($ int $)=0.0356]$ & $3294[R$ (int) $=0.0445]$ \\
\hline completeness to $\theta=25.000^{\circ}$ & $96.4 \%$ & $97.8 \%$ \\
\hline absorption correction & $\begin{array}{l}\text { Semi-empirical from } \\
\text { equivalents }\end{array}$ & $\begin{array}{l}\text { Semi-empirical from } \\
\text { equivalents }\end{array}$ \\
\hline refinement method & $\begin{array}{l}\text { Full-matrix least-squares on } \\
F^{2}\end{array}$ & $\begin{array}{l}\text { Full-matrix least-squares on } \\
F^{2}\end{array}$ \\
\hline data/restraints/parameters & $1884 / 0 / 164$ & 3294 / 1 / 294 \\
\hline goodness-of-fit on $F^{2}$ & 1.054 & 1.000 \\
\hline final $R$ indices $[1>2 \sigma(I)]$ & $R 1=0.0672, w R 2=0.1916$ & $R 1=0.0652, w R 2=0.1444$ \\
\hline$R$ indices (all data) & $R 1=0.0819, w R 2=0.2032$ & $R 1=0.1895, w R 2=0.2009$ \\
\hline absolute structure parameter & $-0.8(10)$ & $0.04(9)$ \\
\hline largest diff. peak and hole & 0.304 and -0.375 e $\AA^{-3}$ & 0.215 and -0.161 e $\AA^{-3}$ \\
\hline
\end{tabular}




\section{FIGURE 1}

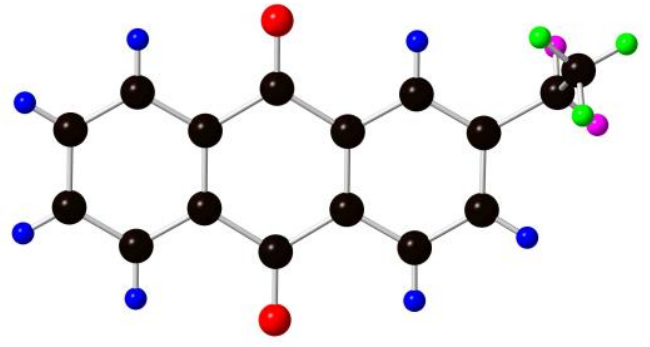

(a)

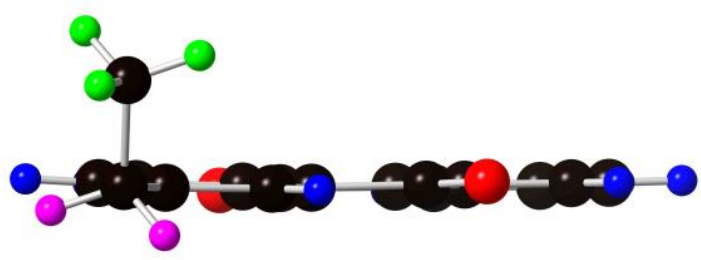

(c)

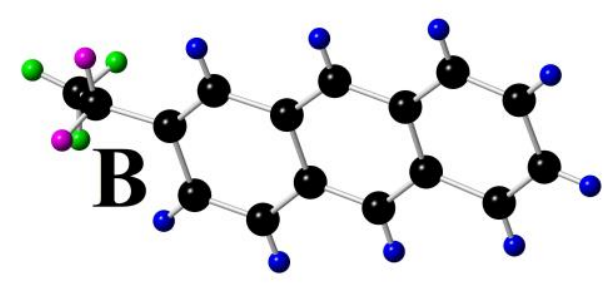

$-\infty-\infty=0-\infty \theta_{8}$

(e)

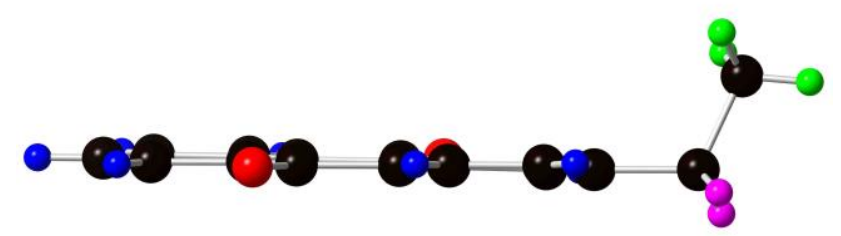

(b)

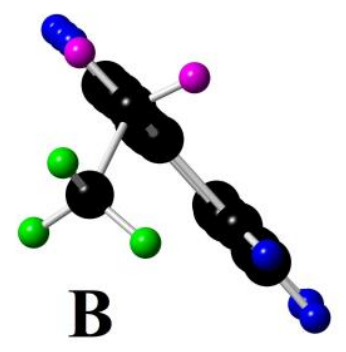

(d)

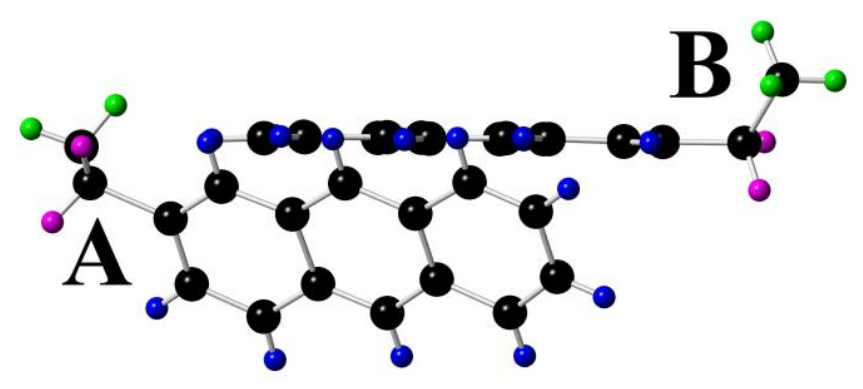


Figure 1. (a), (b) and (c) Three views of the single molecule in the asymmetric unit of 2ethylanthraquinone $(E A Q)$ in the crystal. The single crystal used in the X-ray diffraction experiment was taken from sample EAQ0 (see Table 1) which was not used in any other experiments. (d), (e), and (f) Three views of the two molecules (A and $B$ ) in the asymmetric unit of 2-ethylanthracene (EA) in the crystal. The single crystal used in the $X-$ ray diffraction experiment was taken from sample EA1 (see Table 1) which was used in the NMR relaxation experiments. $\mathrm{C}$ atoms are black, $\mathrm{O}$ atoms are red, methyl group $\mathrm{H}$ atoms are green, other ethyl group $\mathrm{H}$ atoms are magenta, and ring $\mathrm{H}$ atoms are blue. The unique view of the two molecules in the asymmetric unit of EA in (d) puts the two aromatic rings perpendicular to the plane of the page and allows for a comparison with the single molecule in the asymmetric unit in EAQ in (c). The single molecule of EAQ in (b) can be compared with molecule $A$ of EA in (e) and with molecule $B$ of EA in (f). The dihedral angle (C1-C2-C15-C16) is $78^{\circ}$ in EAQ and $107^{\circ}$ (molecule $A$ ) and $123^{\circ}$ (molecule B) in EA. In the text (Section 2.1) we say that in all cases, the methyl group is well out of the aromatic plane $\left[78^{\circ}\right.$ in EAQ and $73^{\circ}$ (molecule A) and $57^{\circ}$ (molecule B) in $E A]$. 
FIGURE 2

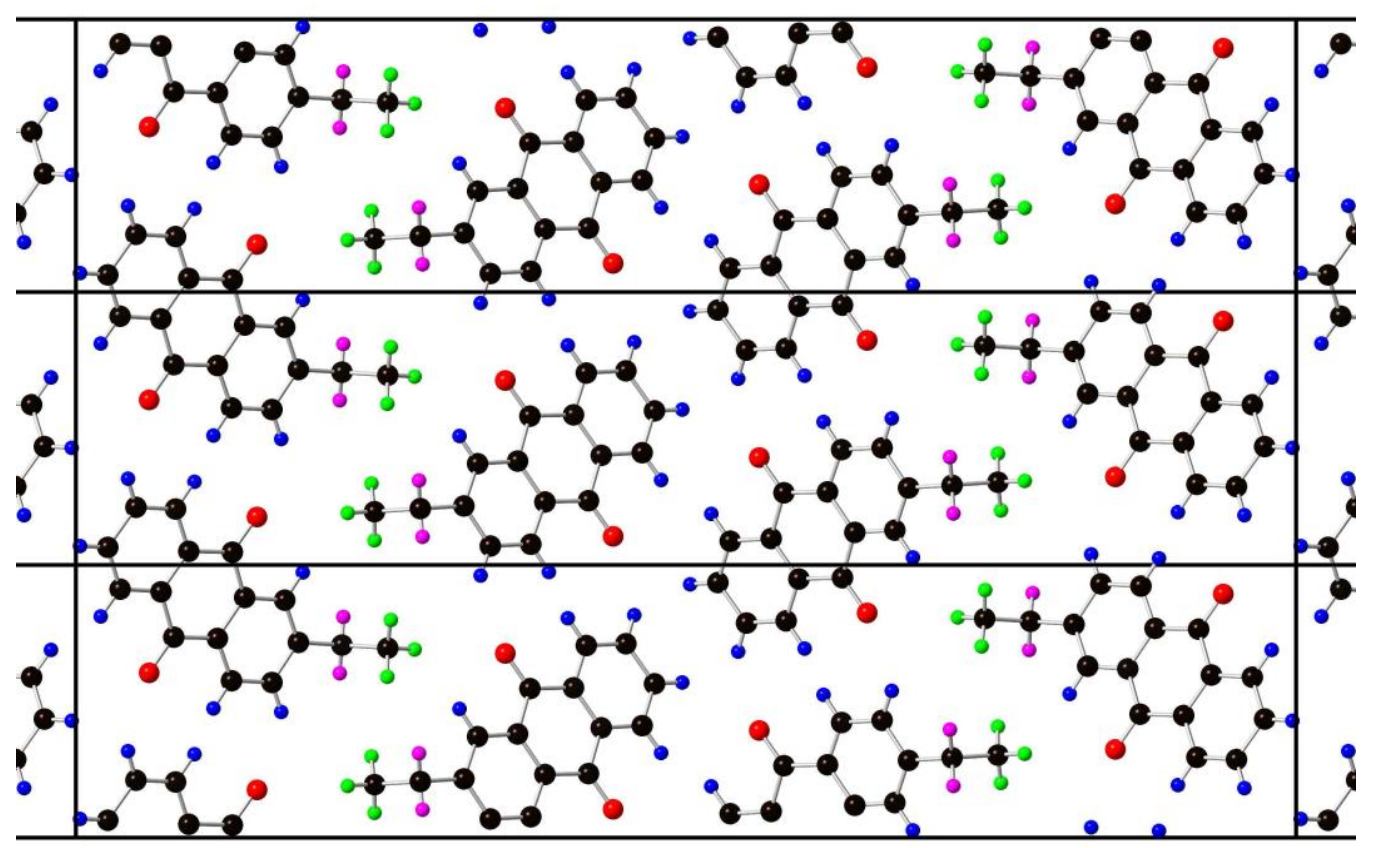

(a)

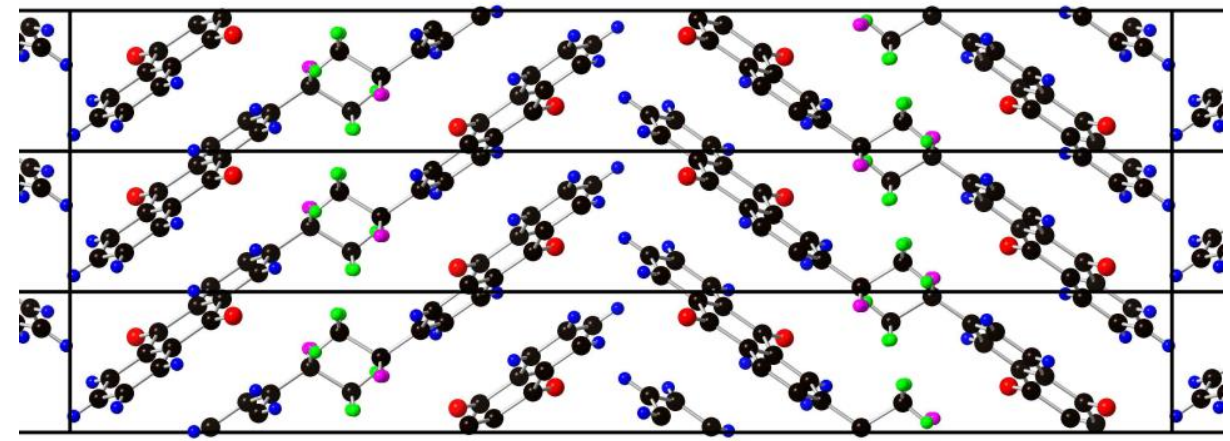

(b) 


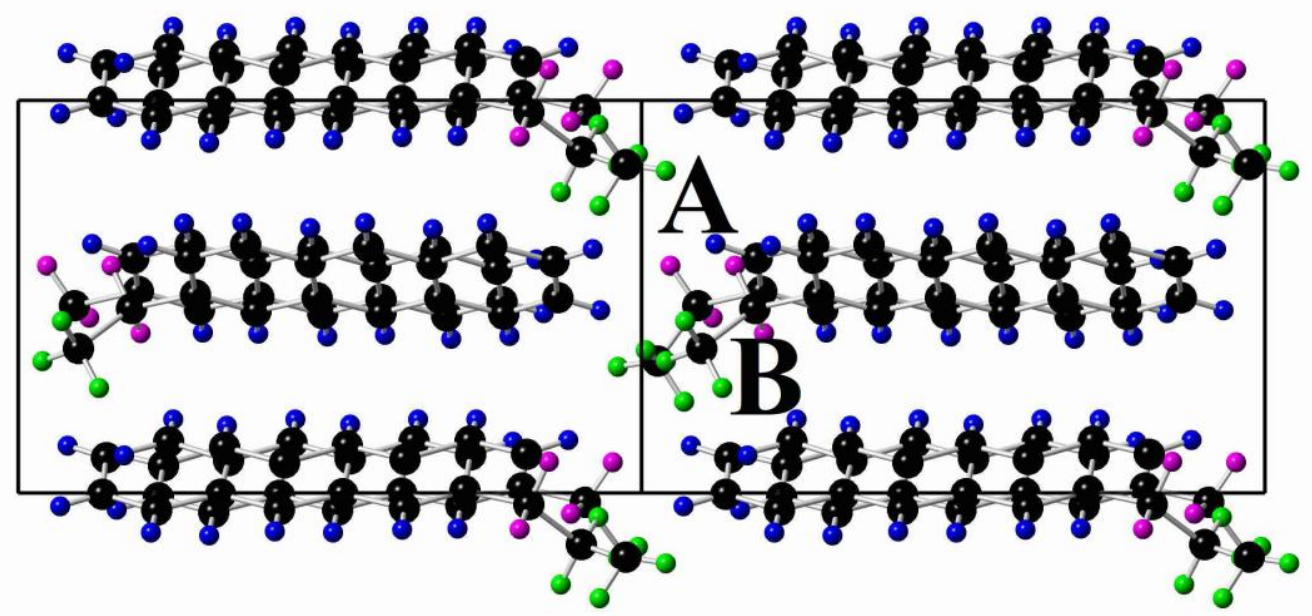

(c)

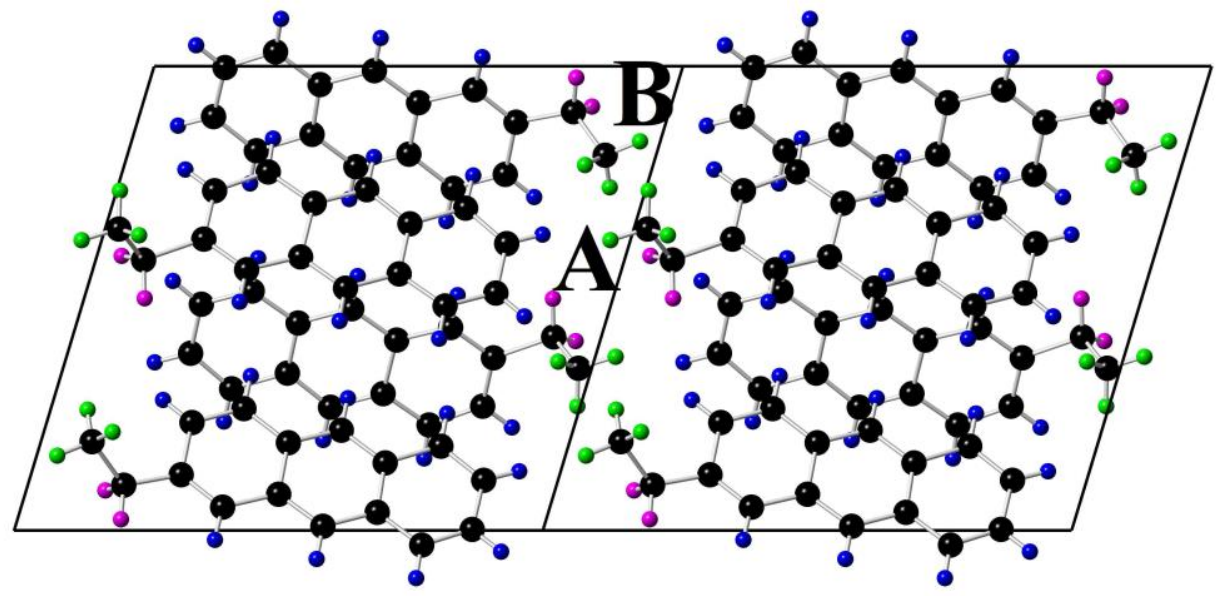

(d) 
Figure 2. The crystal structure of (a) and (b) 2-ethylanthraquinone (EAQ) and of (c) and (d) 2-ethylanthracene (EA) in the (a) and (c) 100 and (b) and (d) 010 planes. See Table 2 for the X-ray parameters. The single crystals used in the X-ray diffraction experiments were taken from samples EAQ0 and EA1 (see Table 1). $C$ atoms are black, $O$ atoms are red, methyl group $\mathrm{H}$ atoms are green, other ethyl group $\mathrm{H}$ atoms are magenta, and ring $\mathrm{H}$ atoms are blue. The asymmetric unit in EAQ (a and $b)$ is a single molecule $(Z=1)$. There are two molecules $(A$ and $B)$ in the asymmetric unit for EA $(Z=2)$ (c and d) and the methyl groups on the two molecules are indicated by $A$ and $B$. Both structures have four molecules in the unit cell $(Z=4)$. The four parts of this figure are not to same scale. 
FIGURE 3

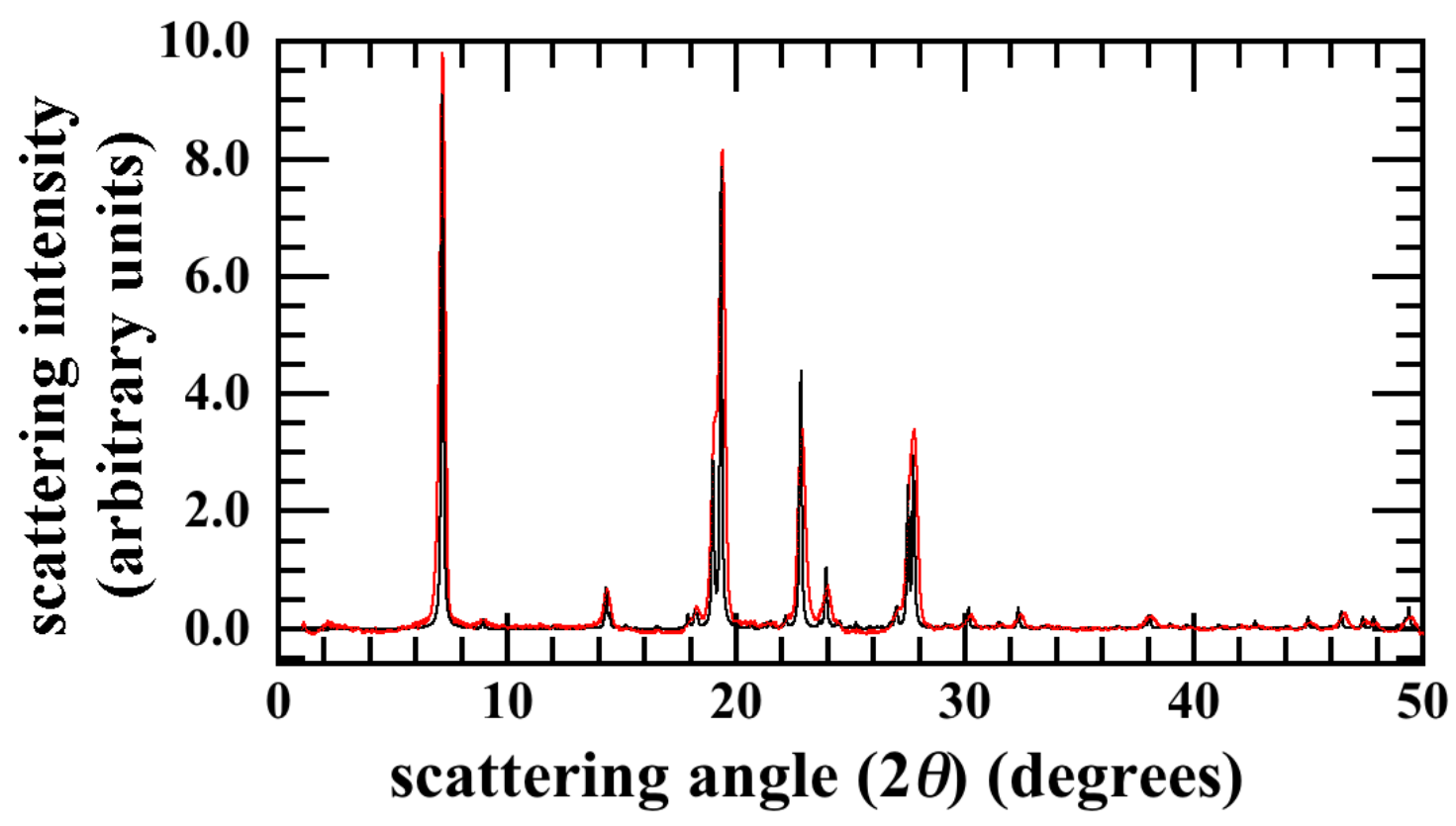

(a)

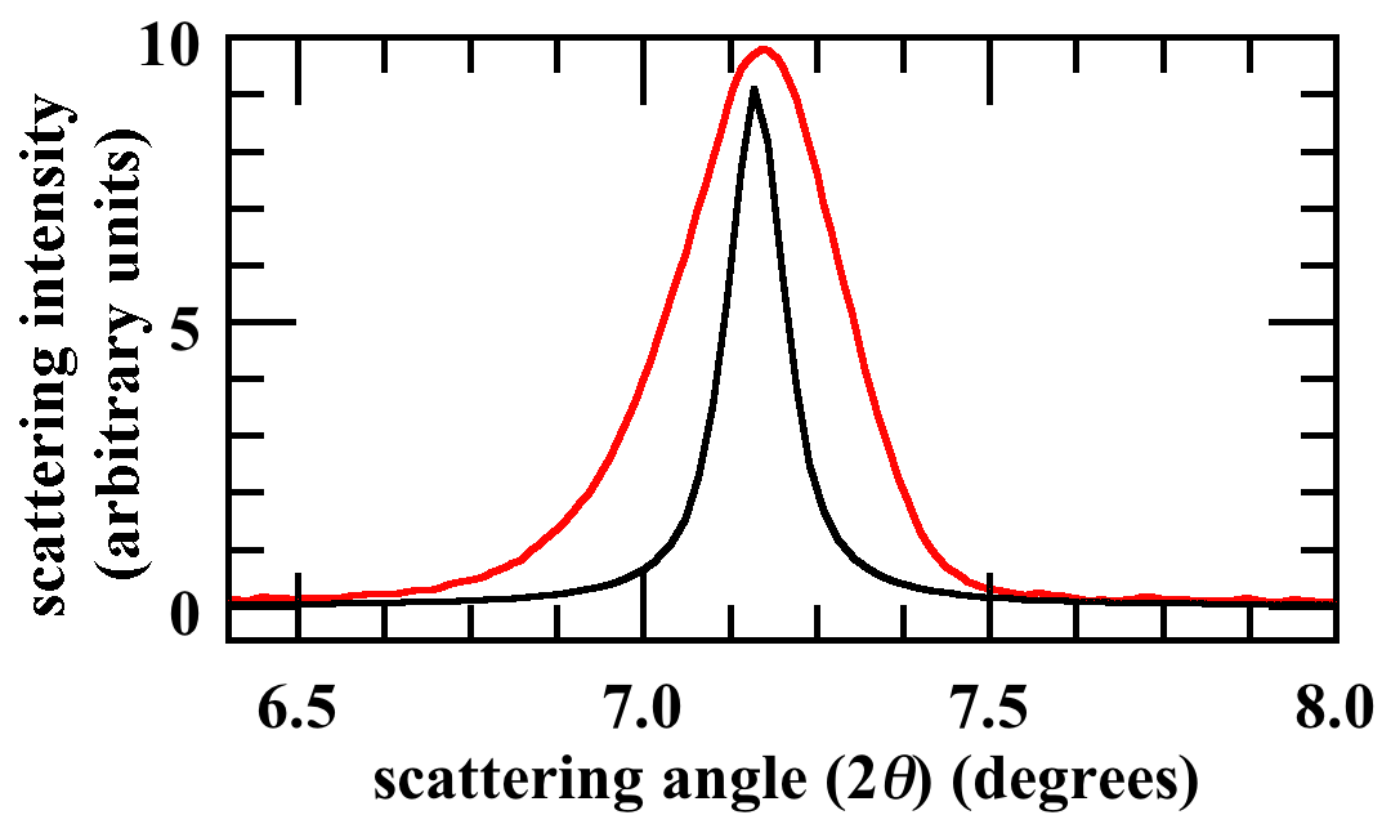

(b) 


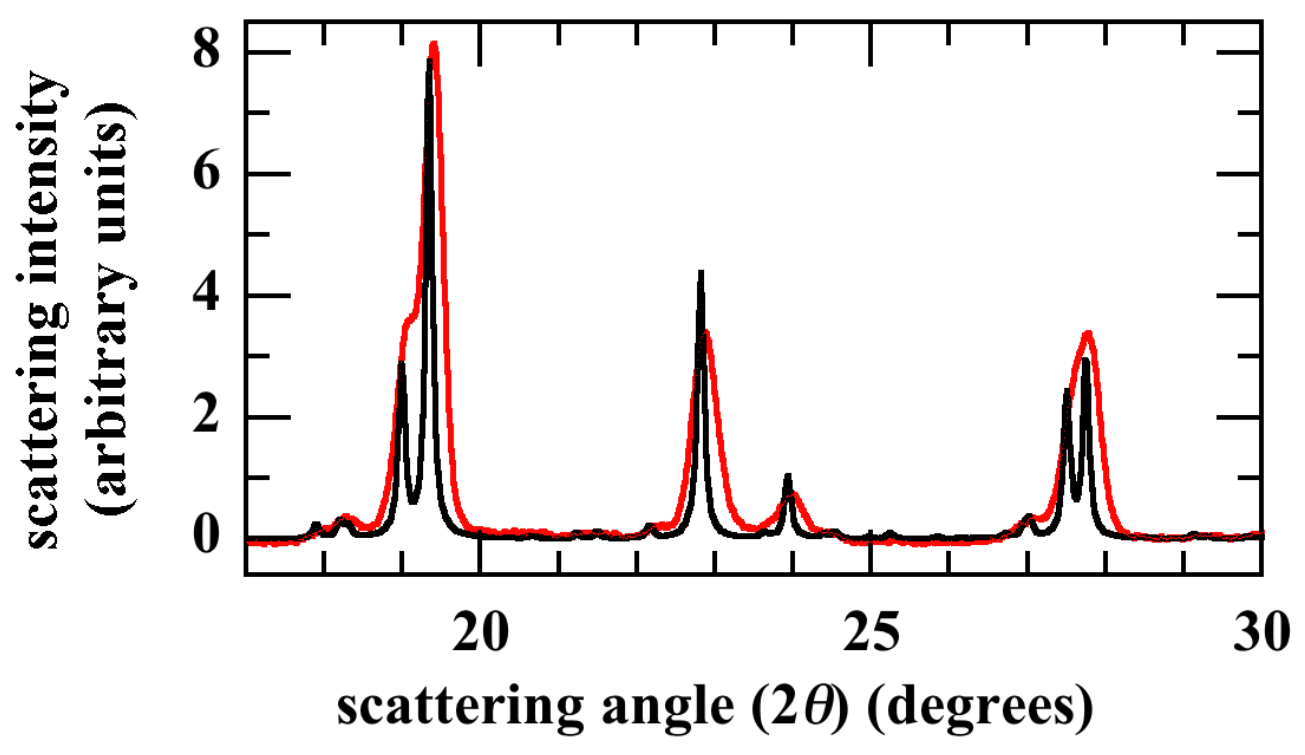

(c)

Figure 3. A comparison of the powder X-ray diffractogram (black) computed from the single crystal X-ray structure (using a small crystal taken from sample EA1) and the experimental powder X-ray diffractogram (red) for about $10 \mathrm{mg}$ of sample EA1 of 2ethylanthracene (EA). (a) The entire diffractogram (0-50色. (b) The region from 6.5-8.0 on an expanded scale. (c) The region from $17-30^{\circ}$ on an expanded scale. The broad background of the experimental powder diffractogram has been removed and the experimental and computed diffractograms have different line broadenings. The vertical scales of the two diffractograms were normalized using the peak at $19.3^{\circ}$. This comparison suggests that the small single crystal taken from sample EA1 for use in the single crystal diffraction experiment is typical of the entire sample. This diffractogram is discussed in the text in Section 2.2. 
FIGURE 4

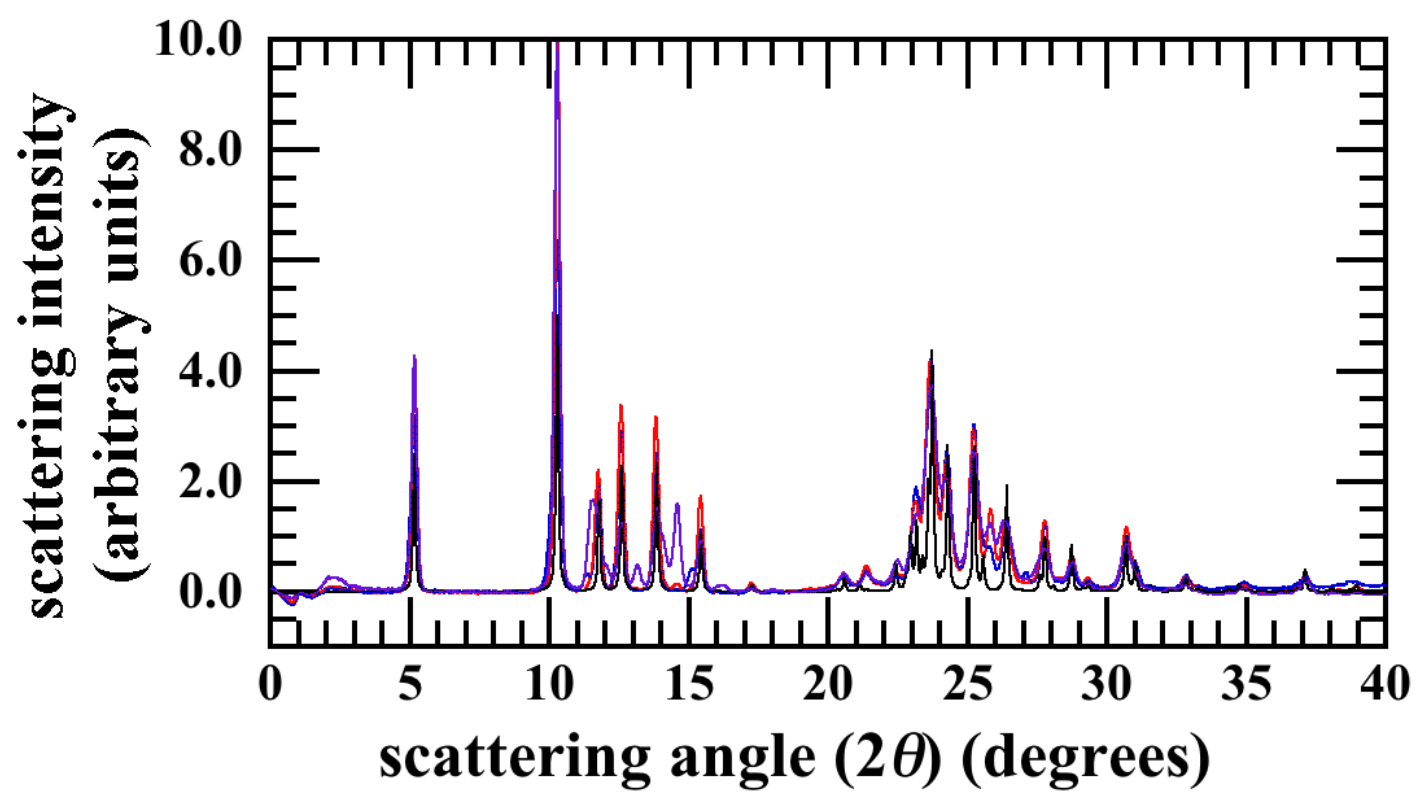

(a)

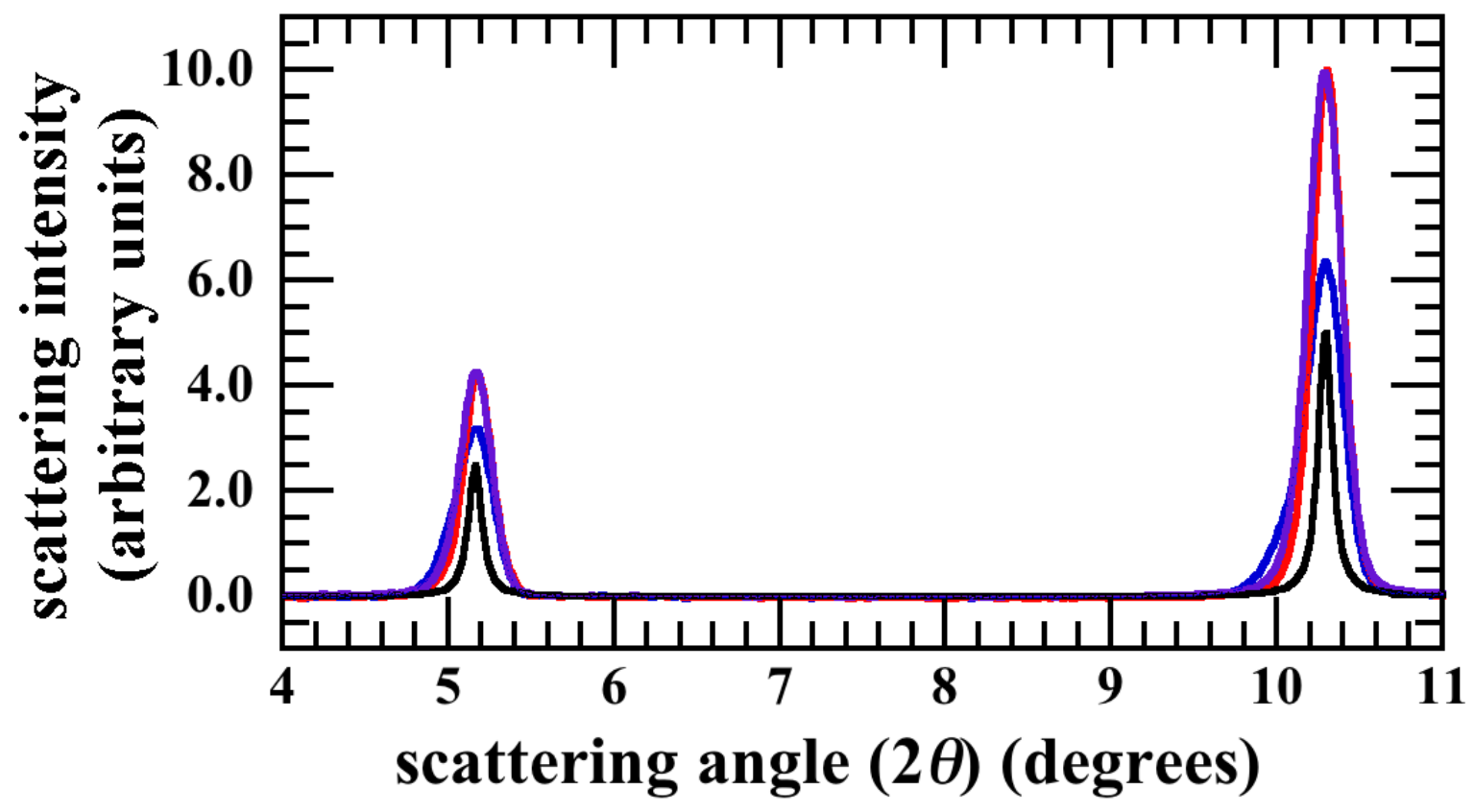

(b) 


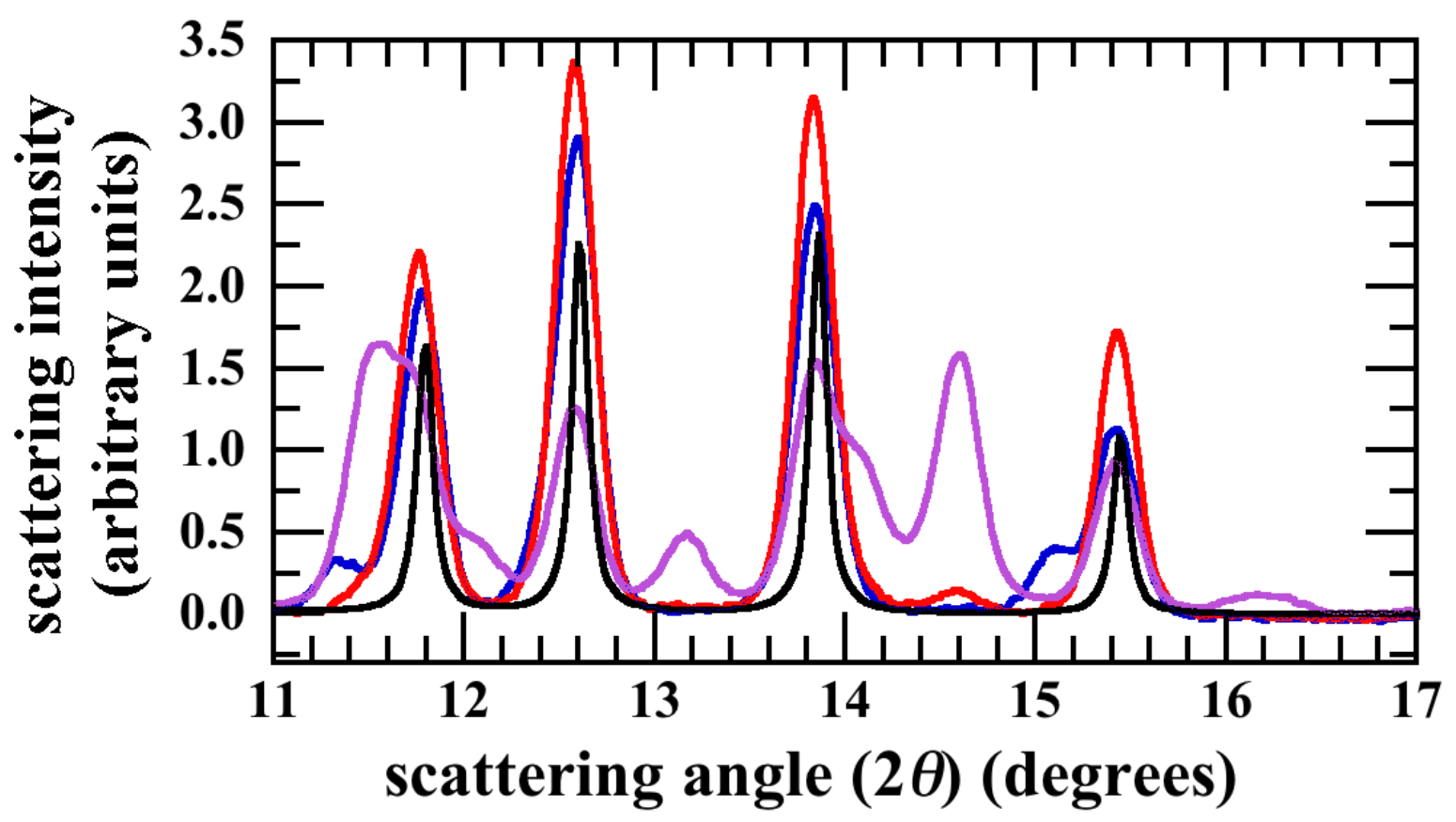

(c)

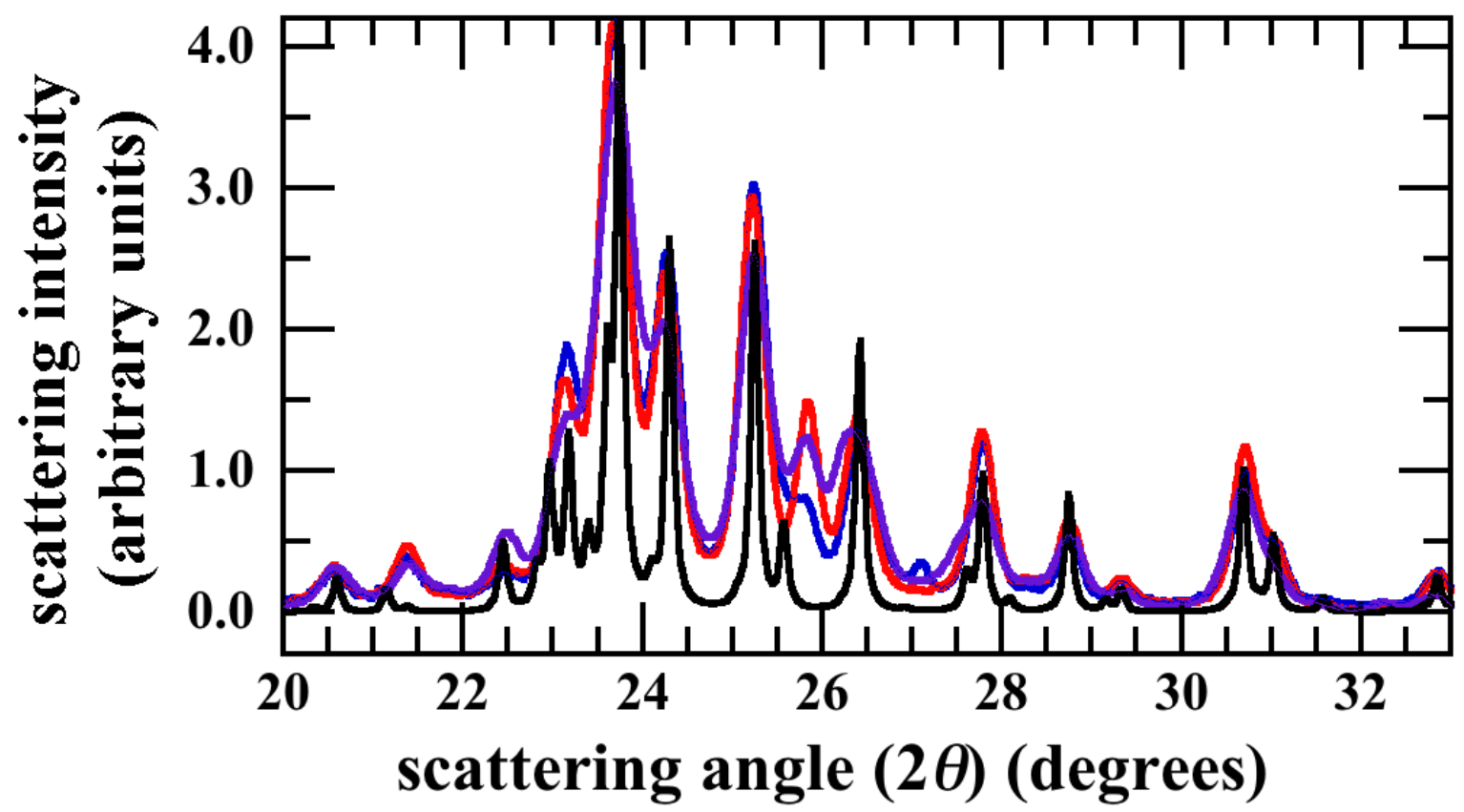

(d) 
Figure 4. A comparison of the powder X-ray diffractogram (black) computed from the single crystal $X$-ray structure (using a crystal from sample EAQ0) and the experimental powder X-ray diffractograms for samples EAQ1 (red), EAQ2 (purple), and EAQ3 (blue) of 2-ethylanthraquinone (EAQ). (a) The entire diffractogram $\left(0-40^{\circ}\right)$. (b) The region from 4$11^{\circ}$ on an expanded scale. (c) The region from $11-17^{\circ}$ on an expanded scale. (d) The region from $20-33^{\circ}$ on an expanded scale. The broad backgrounds of the experimental powder diffractograms have been removed and the experimental and computed diffractograms have different line broadenings. The vertical scales of the four diffractograms were normalized using the peaks in the region $23-32^{\circ}$. The differences among these four diffractograms are discussed in the text in Section 2.2. 
FIGURE 5

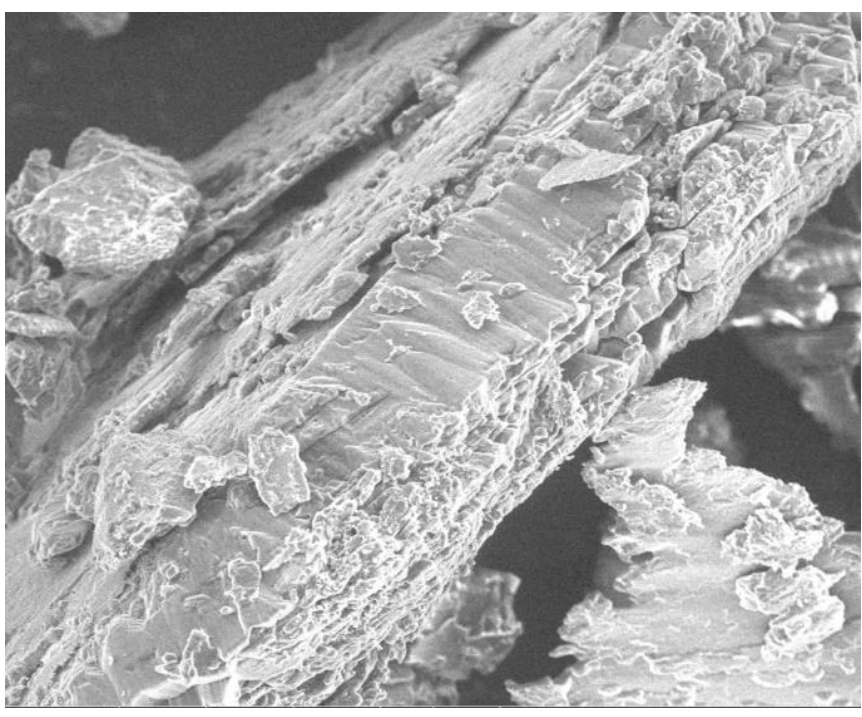

(a)

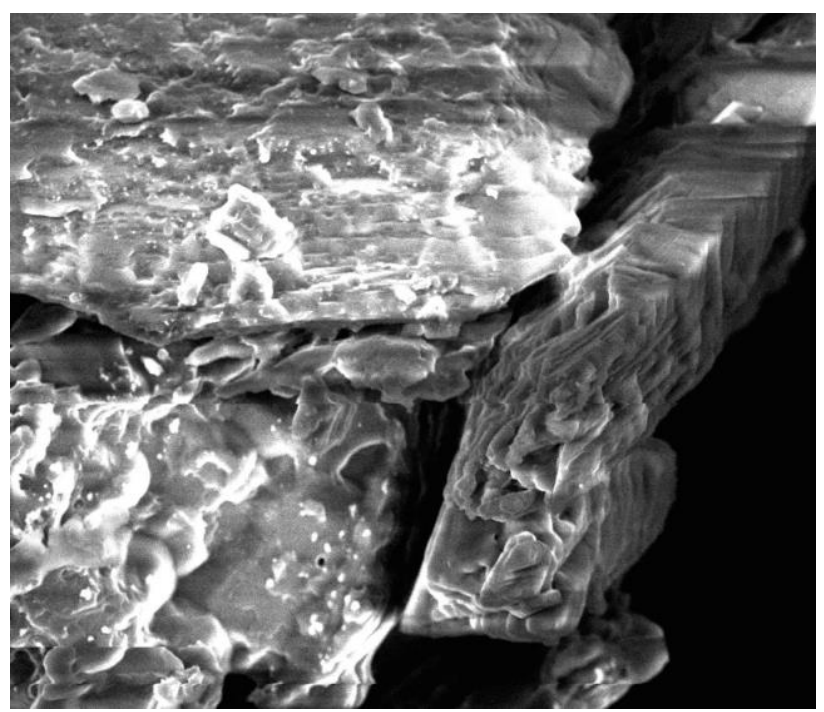

(b)

Figure 5. Scanning electron microscopy images of (a small part of) sample EA1 (see Table 1) of 2-ethylanthracene (EA). (a) A $127 \times 109 \mu \mathrm{m}$ part and (b) a $25 \times 22 \mu \mathrm{m}$ part of the sample. These images are typical of the entire sample. Images using sample EA2 (not shown) are very similar. These images are discussed in Section 2.5. 


\section{FIGURE 6}

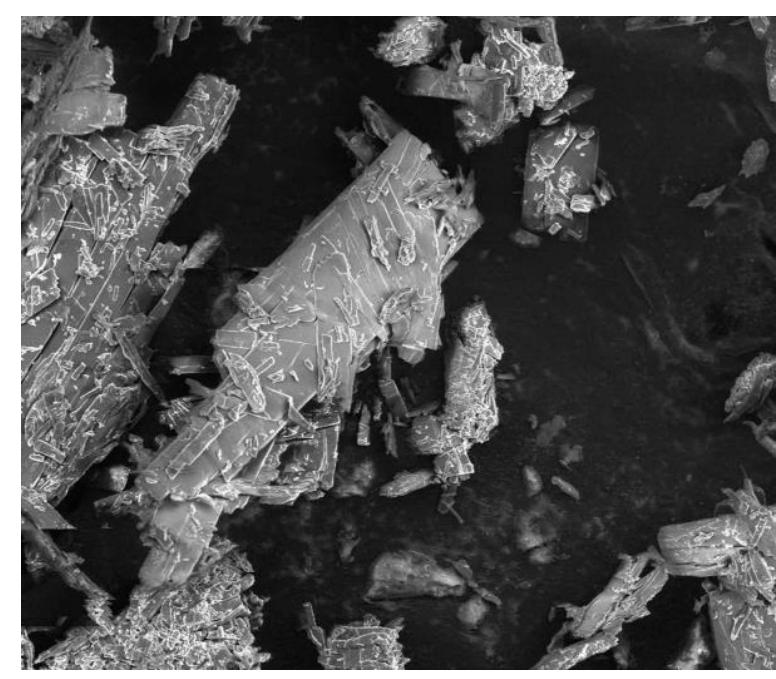

(a)

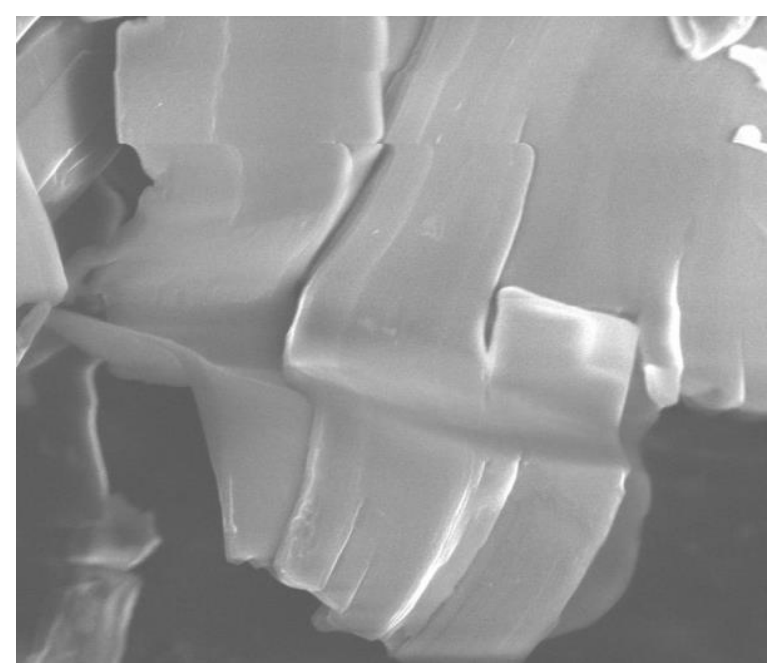

(b)

Figure 6. Scanning electron microscopy images of (a small part of) sample EAQ1 (see Table 1) of 2-ethylanthraquinone (EAQ). (a) A $253 \times 218 \mu \mathrm{m}$ part and (b) a $13 \times 11 \mu \mathrm{m}$ part. These images are typical of the entire sample and are discussed in Section 2.5. 


\section{FIGURE 7}

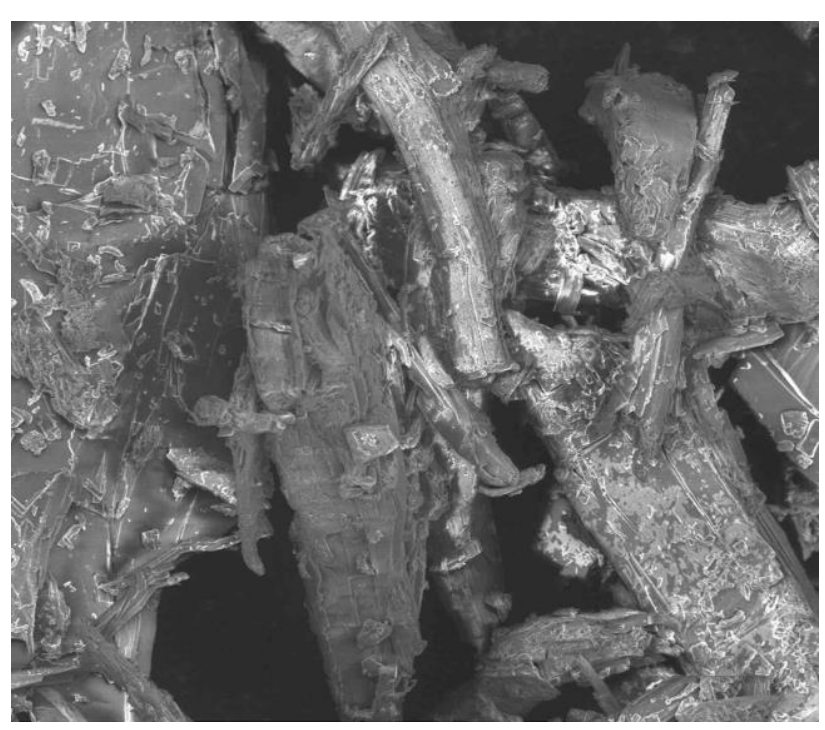

(a)

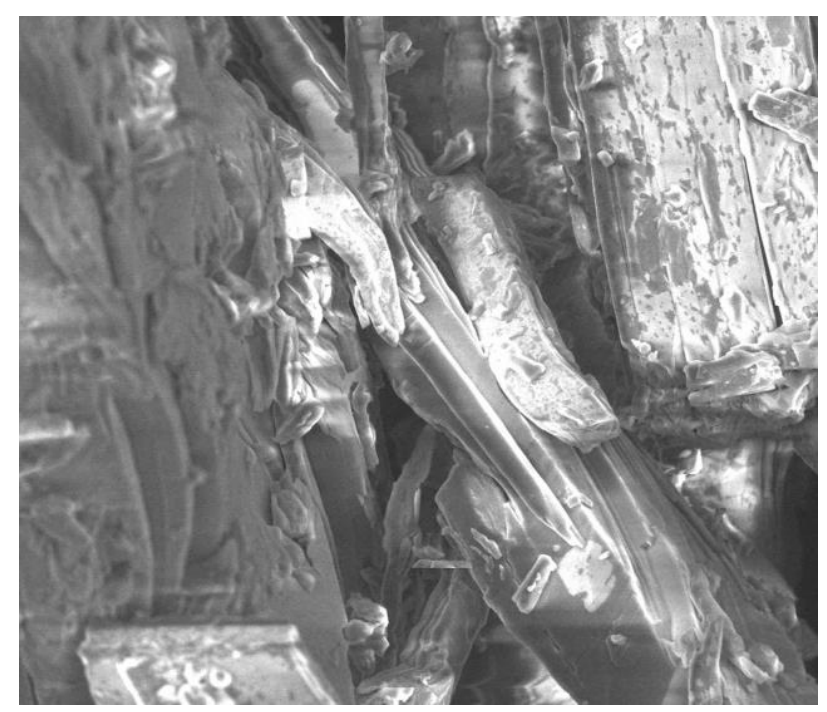

(b)

Figure 7. Scanning electron microscopy images of (a small part of) sample EAQ3 (see Table 1) of 2-ethylanthraquinone (EAQ). (a) A $253 \times 218 \mu \mathrm{m}$ part and (b) a $51 \times 44 \mu \mathrm{m}$ part. These images are typical of the entire sample. Images using sample EA2 (not shown) are very similar. These images are discussed in Section 2.5. 
FIGURE 8

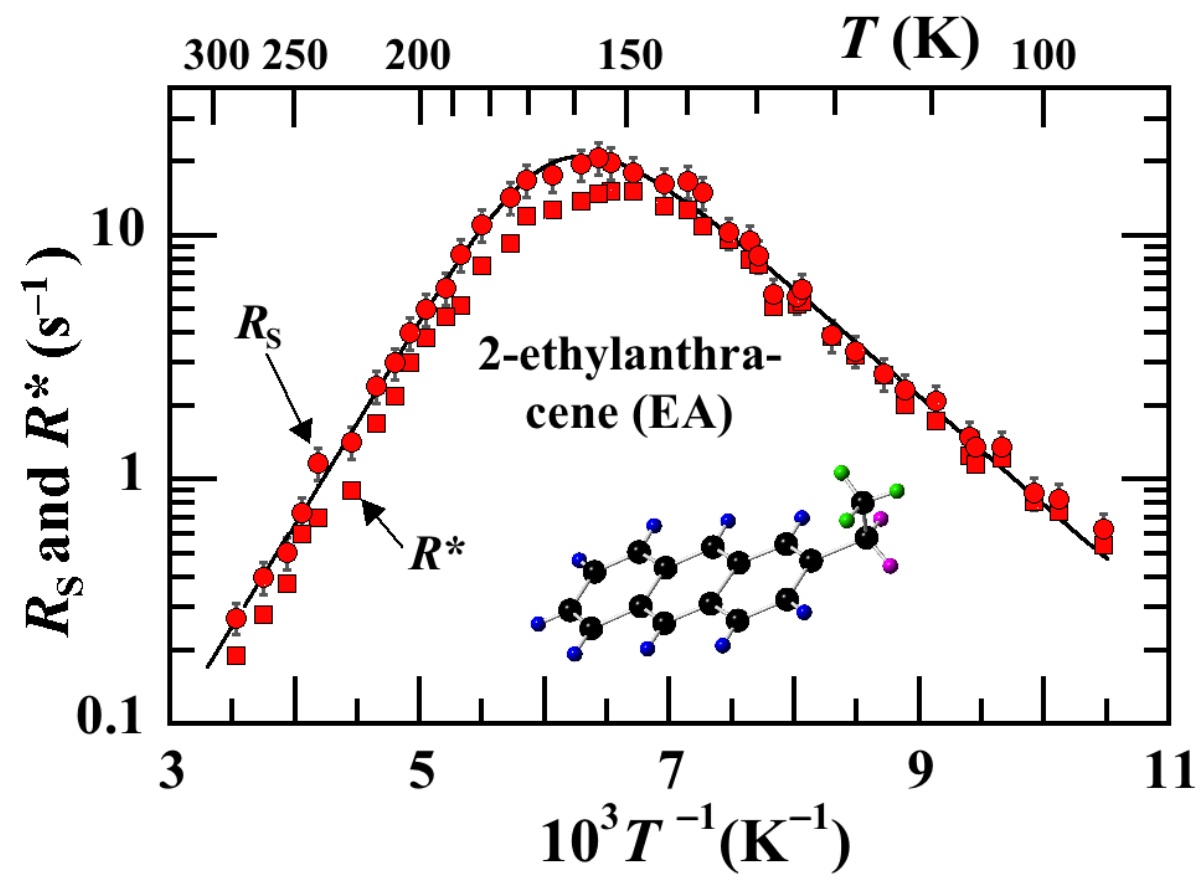

(a)

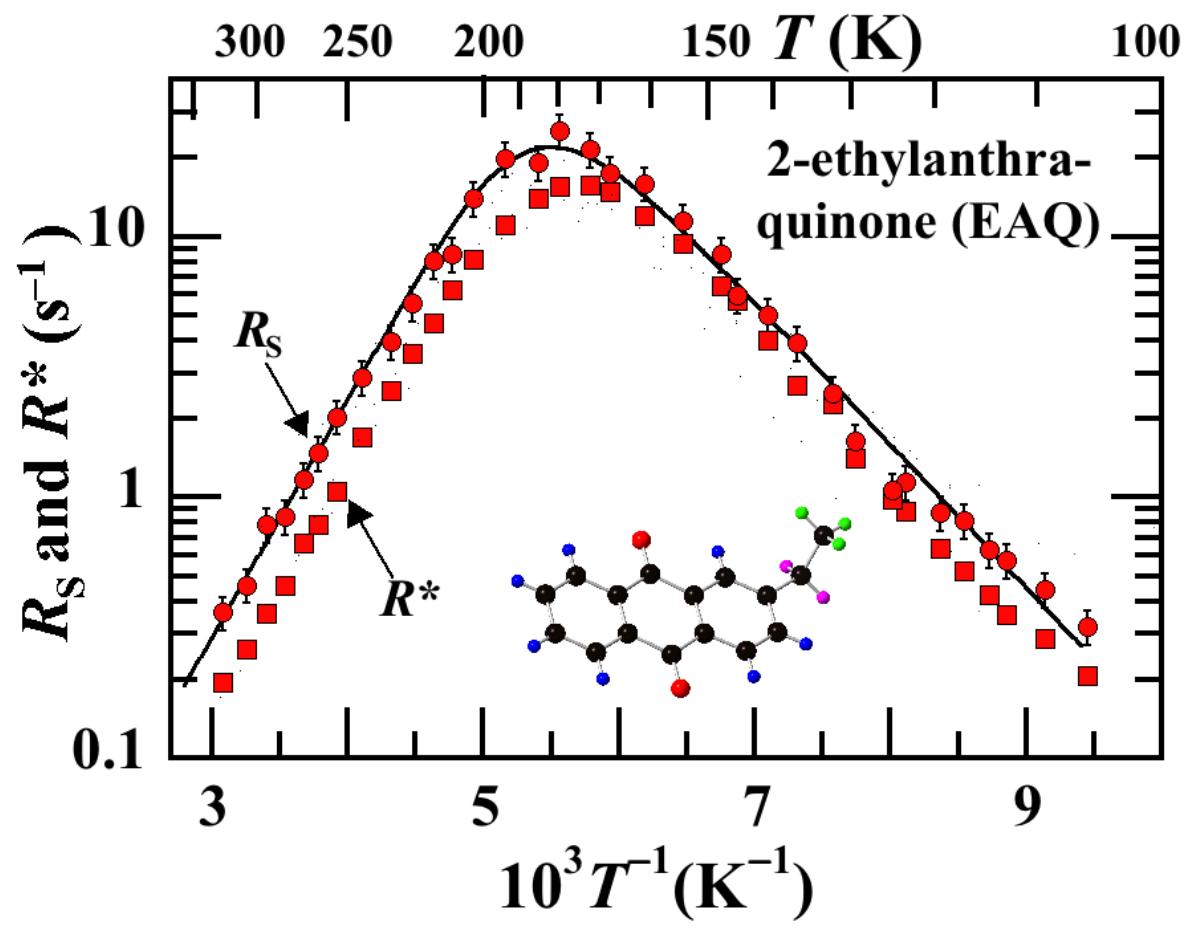

(b) 
Figure 8. The initial ${ }^{1} \mathrm{H}$ spin-lattice relaxation rates $R \mathrm{~s}$ (red circles) and the characteristic relaxation rates $R^{\star}$ (red squares) in (a) sample EA1 of 2-ethylanthracene (EA) and (b) sample EAQ1 of 2-ethylanthraquinone (EAQ) versus inverse temperature $T^{-1}$ at an NMR frequency of $22.5 \mathrm{MHz}$. The uncertainty bars for the $R^{\star}$ values are within the sizes of the squares. These $R^{\star}$ values for sample EA1 are also shown in Figure $9 \mathrm{a}$ and those for sample EAQ1 are also shown in Figure 10a, both using the same symbols and colors used here. The solid lines are fits to $R$ s using the model discussed in Section 2.6.2. The $R^{\star}$ values are discussed in Section 2.6.4. 
FIGURE 9

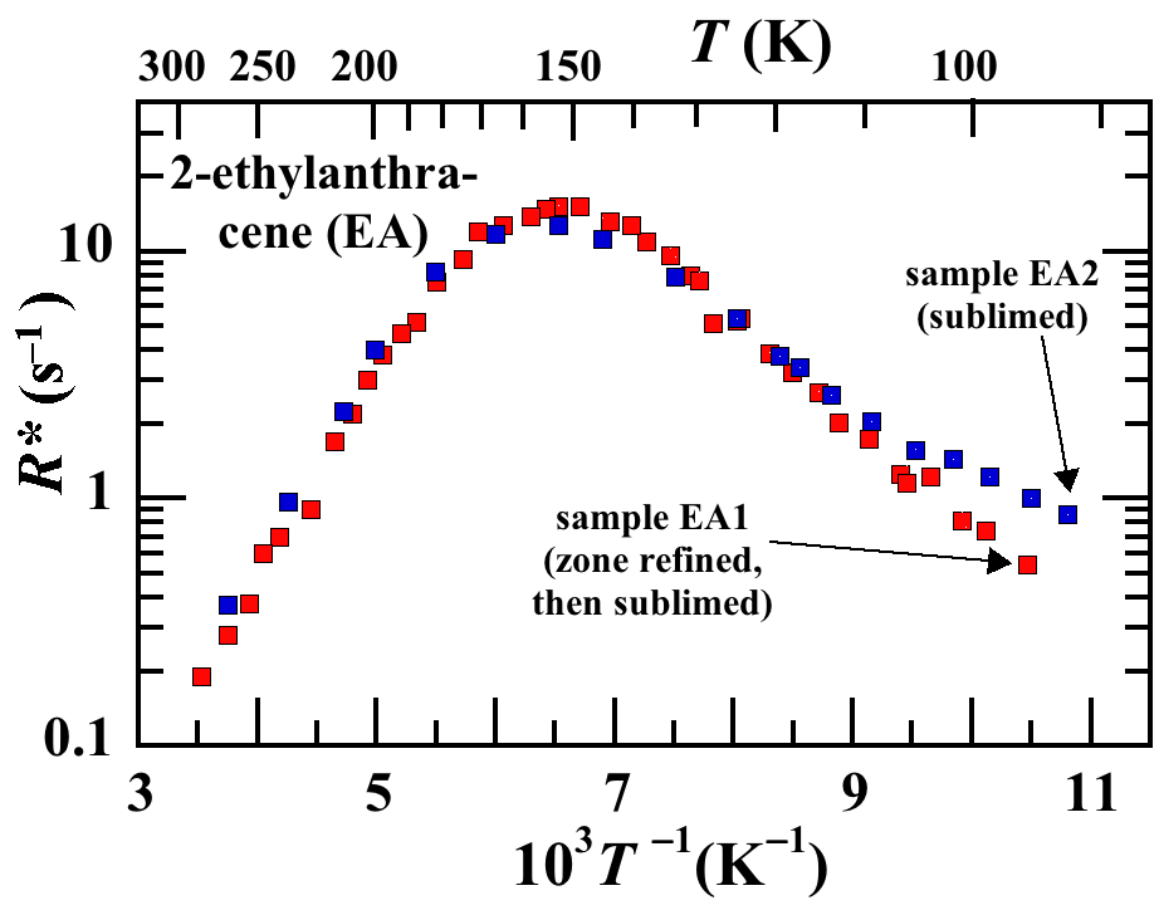

(a)

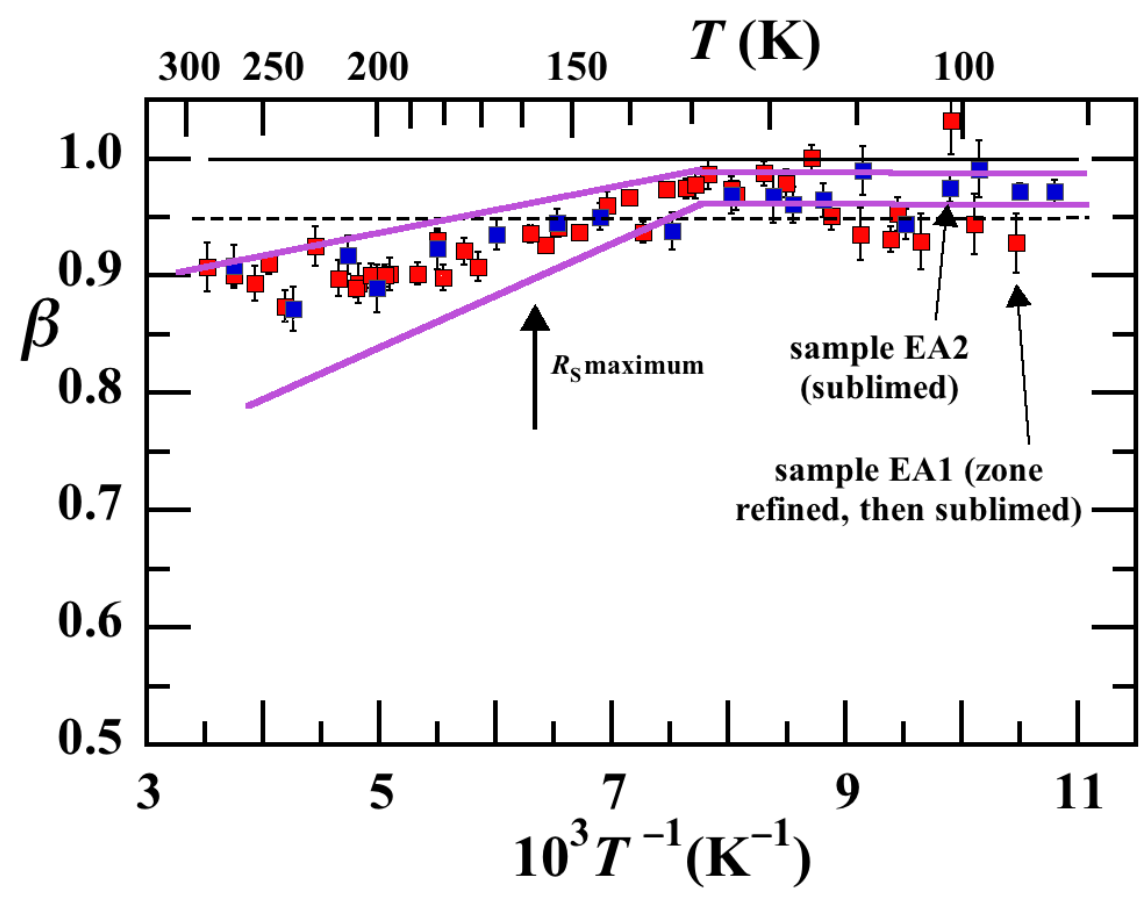

(b) 
Figure 9. (a) The characteristic ${ }^{1} \mathrm{H}$ spin-lattice relaxation rates $R^{\star}$ and (b) the stretching parameter $\beta$ in a stretched exponential fit $M(t)=M(\infty)+[M(0)-M(\infty)]\left[\exp \left\{-\left(R^{\star} t\right)^{\beta}\right\}\right]$ of the relaxing ${ }^{1} \mathrm{H}$ magnetization following a perturbation for samples EA1 (red squares) and EA2 (blue squares) of 2-ethylanthracene (EA) versus inverse temperature $T^{-1}$ at an NMR frequency of $22.5 \mathrm{MHz}$. In (a) the uncertainty bars are within the sizes of the symbols. In (b), the arrow indicates the temperature of the maximum in Rs in sample EA1 in Figure 8a. In (b) the solid horizontal line at $\beta=1$ corresponds to exponential relaxation. For $\beta>0.95$ (horizontal dashed line), it is difficult to ascertain that the relaxation is nonexponential to within experimental uncertainty on an experiment-by-experiment basis. The purple lines define the region where $\beta$ is expected to fall if a single type of methyl group rotation is responsible for the rotation as discussed in Section 2.6.4. 
FIGURE 10

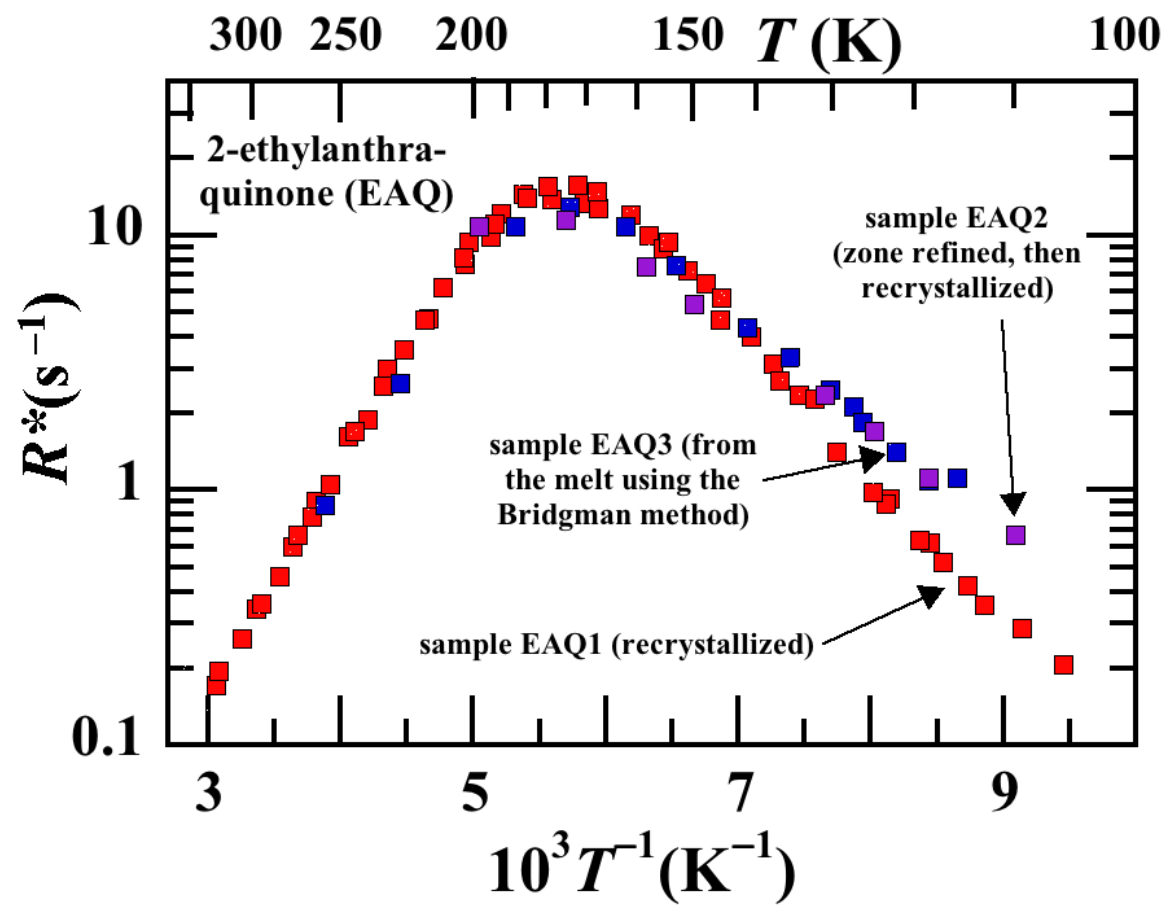

(a)

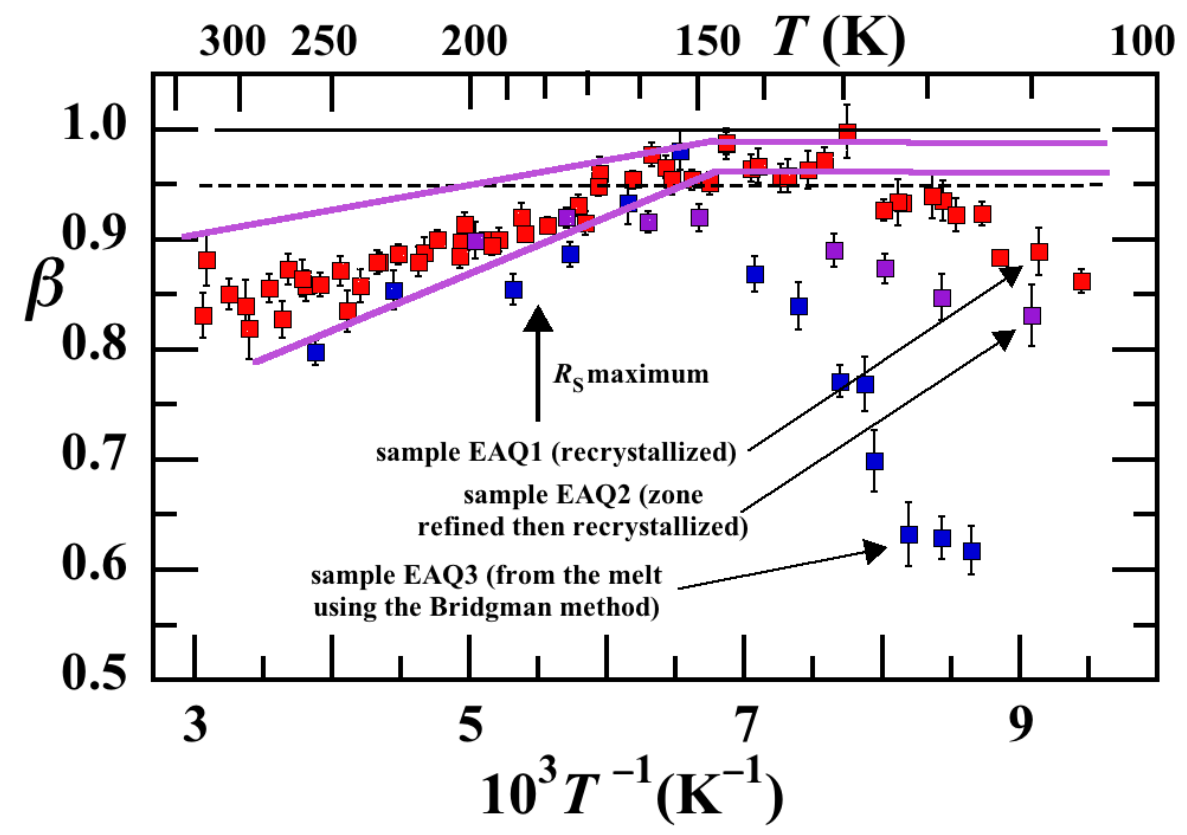

(b) 
Figure 10. (a) The characteristic ${ }^{1} \mathrm{H}$ spin-lattice relaxation rates $R^{\star}$ and (b) the stretching parameter $\beta$ in a stretched exponential fit $M(t)=M(\infty)+[M(0)-M(\infty)]\left[\exp \left\{-\left(R^{\star} t\right)^{\beta}\right\}\right]$ of the relaxing ${ }^{1} \mathrm{H}$ magnetization following a perturbation for samples EAQ1 (red squares), EAQ2 (purple squares), and EAQ3 (blue squares) of 2-ethylanthraquinone (EAQ) versus inverse temperature $T^{-1}$ at an NMR frequency of $22.5 \mathrm{MHz}$. In (a) the uncertainty bars are within the sizes of the symbols. In (b), the arrow indicates the temperature of the maximum in $R \mathrm{~s}$ in sample EAQ1 in Figure $8 \mathrm{~b}$. In (b) the solid horizontal line at $\beta=1$ corresponds to exponential relaxation. For $\beta>0.95$ (horizontal dashed line), it is difficult to ascertain that the relaxation is nonexponential to within experimental uncertainty on an experiment-by-experiment basis. The purple lines define the region where $\beta$ is expected to fall if a single type of methyl group rotation is responsible for the rotation as discussed in Section 2.6.4. 
FIGURE 11

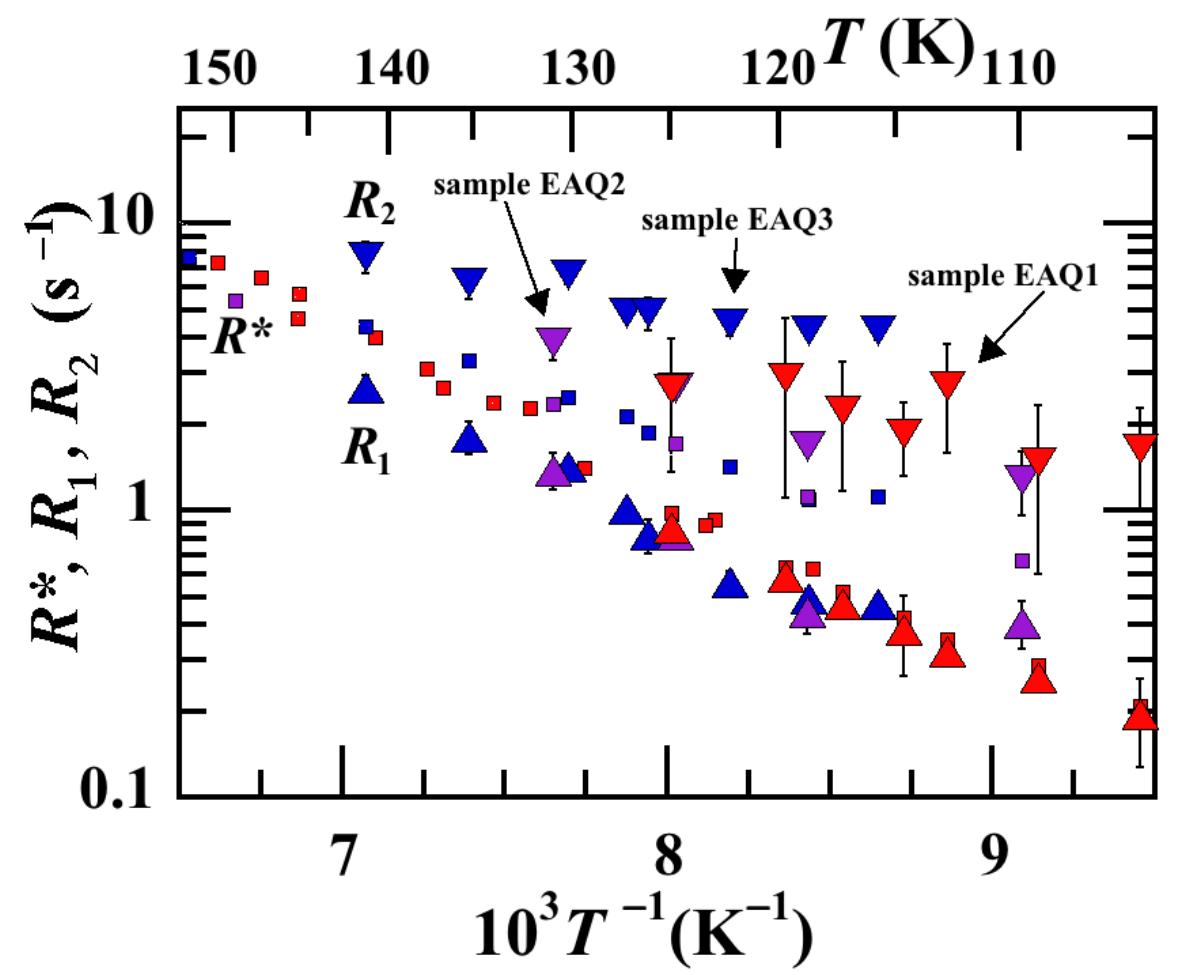

(a)

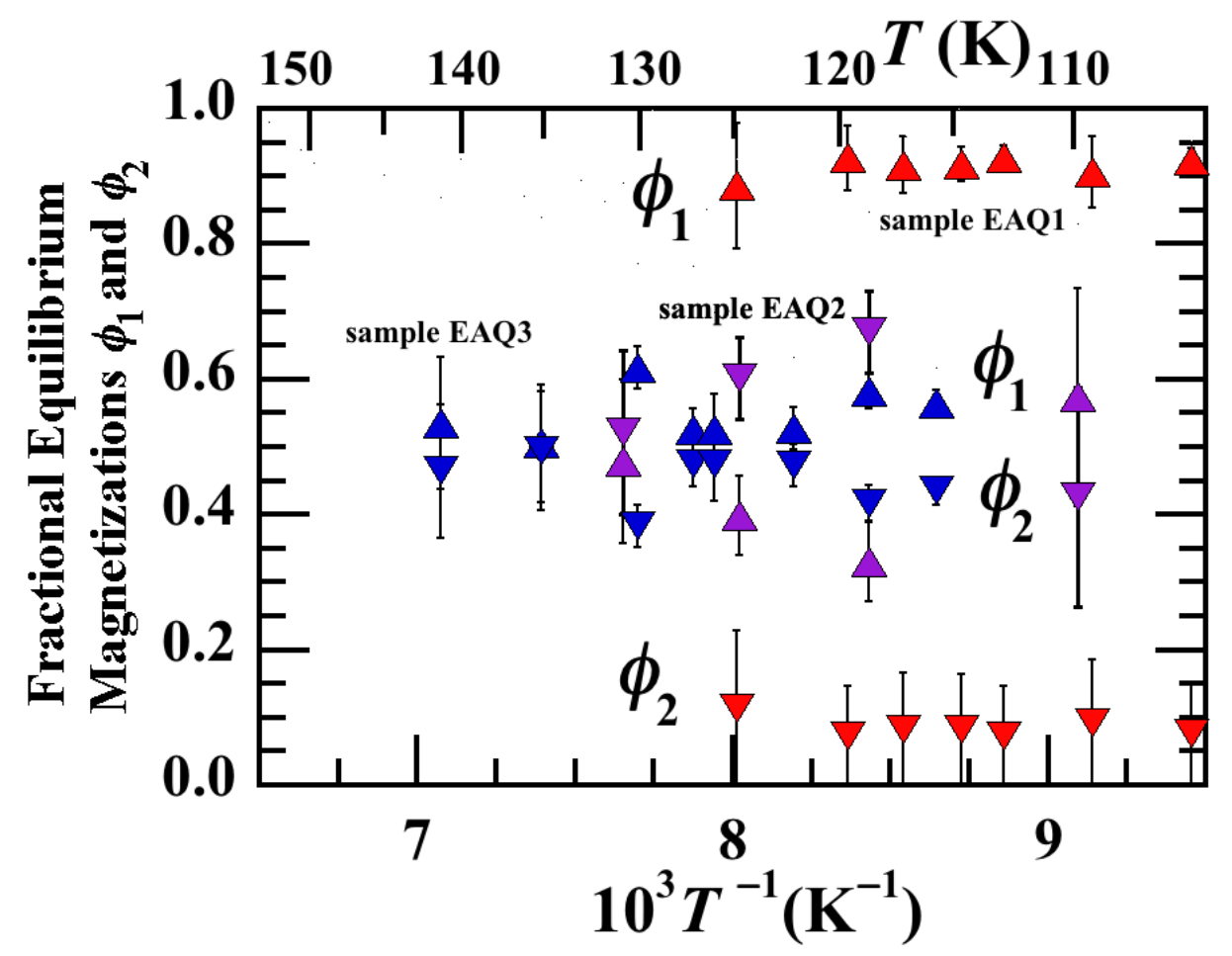

(b) 
Figure 11. (a) The relaxation rates $R_{1}$ (upward-pointing triangles) and $R_{2}$ (downwardpointing triangles) in a double exponential relaxation process and (b) the equilibrium fractional magnetizations $\phi_{1}$ (upward-pointing triangles) and $\phi_{2}$ (downward-pointing triangles) relaxing with these two rates for samples EAQ1 (red), EAQ2 (purple), and EAQ3 (blue) of 2-ethylanthraquinone (EAQ) versus inverse temperature $T^{-1}$ at temperatures below $142 \mathrm{~K}$ at an NMR frequency of $22.5 \mathrm{MHz}$. These parameters are discussed in Section 2.6.5. In (a) the characteristic rates $R^{\star}$ from Figure 10a are indicated by small squares for comparison. 